\title{
The Immunomodulatory CEA Cell Adhesion Molecule 6 (CEACAM6/CD66c) Is a Protein Receptor for the Influenza A Virus
}

\author{
Shah Kamranur Rahman 1,2,*, Mairaj Ahmed Ansari ${ }^{3,+}$, Pratibha Gaur ${ }^{4}$ (D, Imtiyaz Ahmad ${ }^{1}$ (D), \\ Chandrani Chakravarty ${ }^{1}$, Dileep Kumar Verma ${ }^{1}$, Anshika Sharma ${ }^{5}$, Sanjay Chhibber ${ }^{6}$, Naila Nehal ${ }^{7}$, \\ Dagmar Wirth ${ }^{4}$ and Sunil K. Lal ${ }^{1,5, *(\mathbb{D})}$
}

Citation: Rahman, S.K.; Ansari, M.A.; Gaur, P.; Ahmad, I.; Chakravarty, C.; Verma, D.K.; Sharma, A.; Chhibber, S.; Nehal, N.; Wirth, D.; et al. The

Immunomodulatory CEA Cell Adhesion Molecule 6 (CEACAM6) CD66c) Is a Protein Receptor for the Influenza A Virus. Viruses 2021, 13, 726. https://doi.org/10.3390/ v13050726

Academic Editor: Abdul A. Waheed

Received: 1 April 2021

Accepted: 10 April 2021

Published: 21 April 2021

Publisher's Note: MDPI stays neutral with regard to jurisdictional claims in published maps and institutional affiliations.

Copyright: (C) 2021 by the authors. Licensee MDPI, Basel, Switzerland. This article is an open access article distributed under the terms and conditions of the Creative Commons Attribution (CC BY) license (https:/ / creativecommons.org/licenses/by/ $4.0 /)$.
1 Virology Group, International Centre for Genetic Engineering \& Biotechnology, New Delhi 110067, India; iaqaiser@gmail.com (I.A.); chandranic29@gmail.com (C.C.); dileep21feb@gmail.com (D.K.V.)

2 Department of Infection Biology, London School of Hygiene \& Tropical Medicine, Keppel Street, London WC1E 7HT, UK

3 H. M. Bligh Cancer Research Laboratories, Department of Microbiology and Immunology, Chicago Medical School, Rosalind Franklin University of Medicine and Science, North Chicago, IL 60064, USA; mairaj01@gmail.com

4 Helmholtz Centre for Infection Research, 38124 Braunschweig, Germany; pratibhagaur@gmail.com (P.G.); dagmar.wirth@helmholtz-hzi.de (D.W.)

5 School of Science, Monash University, Bandar Sunway 47500, Selangor DE, Malaysia; Anshika.Sharma@monash.edu

6 Microbiology Department, Panjab University, Chandigarh 160014, India; sanjaychhibber@pu.ac.in

7 Career Institute of Medical \& Dental Sciences and Hospital, Lucknow 226020, India; drnailanehal@gmail.com

* Correspondence: shah.rahman@lshtm.ac.uk (S.K.R.); sunil.lal@monash.edu (S.K.L.); Tel.: +44-(0)20-7927-4822 (S.K.R.); +60-35-515-9606 (S.K.L.)

+ Present address: Host Pathogen Interaction Laboratory, Department of Biotechnology, SCLS, Jamia Hamdard, New Delhi 110062, India.

Abstract: To establish a productive infection in host cells, viruses often use one or multiple host membrane glycoproteins as their receptors. For Influenza A virus (IAV) such a glycoprotein receptor has not been described, to date. Here we show that IAV is using the host membrane glycoprotein CD66c as a receptor for entry into human epithelial lung cells. Neuraminidase (NA), a viral spike protein, binds to CD66c on the cell surface during IAV entry into the host cells. Lung cells overexpressing CD66c showed an increase in virus binding and subsequent entry into the cell. Upon comparison, CD66c demonstrated higher binding capacity than other membrane glycoproteins (EGFR and DC-SIGN) reported earlier to facilitate IAV entry into host cells. siRNA mediated knockdown of CD66c from lung cells inhibited virus binding on cell surface and entry into cells. Blocking CD66c by antibody on the cell surface resulted in decreased virus entry. We found that CD66c is a specific glycoprotein receptor for influenza A virus that did not affect entry of non-IAV RNA virus (Hepatitis $C$ virus). Finally, IAV pre-incubated with recombinant CD66c protein when administered intranasally in mice showed decreased cytopathic effects in mice lungs. This publication is the first to report CD66c (Carcinoembryonic cell adhesion molecule 6 or CEACAM6) as a glycoprotein receptor for Influenza A virus.

Keywords: virus; lipid raft; flu; influenza A Virus; receptor; neuraminidase; hemagglutinin; carcinoembryonic antigen (CEA); carcinoembryonic cell adhesion molecule (CEACAM); CEACAM6; CD66c; IgG super family; sialic acid

\section{Introduction}

The outermost surface of mammalian cells typically bears a covering of branched sugar residues (oligosaccharides) that allow a wide range of interactions with different 
biomolecules (hormones, cytokines, growth factors, etc.) of the matrix [1]. These oligosaccharides are often linked to membrane proteins (glycoproteins) or lipid (gangliosides) at the cell surface. The type of sugar residues and their branching is responsible for deciding the specificity of oligosaccharides towards biomolecules coming in contact with the cell surface. These interactions between oligosaccharides and biomolecules play a diverse physiological role and are important in maintaining communication and transport of molecules between the cell and its surroundings [2]. Many of these oligosaccharide chains bear sialic acid (SIA) at the termini, which serve as a regulator of molecular and cellular interactions [3].

In general, viruses often breach this communication and bind to terminal SIA as the first step to invade cells [4]. This less specific interaction of viruses with terminal SIA is followed by a more specific interaction of viral spike proteins with a subset of host glycoprotein receptors that effectively accompany the virus into cells and drive the ingested cargo to destined endocytic pathways or intracellular routings [5].

The mechanism of Influenza A Virus (IAV) entry still remains elusive. Information on a host glycoprotein receptor that can pull viruses into the cell is largely unknown. Most of the published literature on influenza entry centers on the early attachment factor, viz. oligosaccharides. The importance of the role of SIA in IAV entry has been documented as early as 1959 [6]; however, there are reports showing IAV entry into host cells even in the absence of SIA [7-9]. Interestingly, De Vries et. al. and Chu et. al. in their studies suggested that while SIAs $(\alpha 2-6, \alpha 2-3)$ may help in the attachment of virus, a specific subset of glycoprotein receptor is necessary for virus entry, which is yet unidentified $[8,9]$. Over the years, a few membrane glycoproteins like EGFR (epidermal growth factor receptor), LSIGN (liver/lymph node-specific intracellular adhesion molecules-3 grabbing non-integrin) and DC-SIGN (Dendritic Cell-Specific Intercellular adhesion molecule-3-Grabbing Nonintegrin) were reported to facilitate viral attachment and entry but were not designated as a receptor for IAV, possibly due to lack of evidence that they play a major role in IAV uptake $[7,10]$. Moreover, the evidence of their physical interaction with IAV spike proteins, Hemagglutinin (HA) and Neuraminidase (NA), at the cell surface or inside the cell was not well characterized. Generally, the role of glycoproteins EGFR, L-SIGN and DC-SIGN in the cellular uptake of the virus is believed to be a low-specificity phenomenon since these surface proteins facilitate uptake of a number of viruses [11]. A comparative study showing specificity of these glycoproteins towards IAV and no other viruses was not demonstrated.

In this report, we have identified a glycoprotein receptor for IAV entry into lung epithelial cells. Earlier, we published a detailed account of an interaction between NA and a host membrane glycoprotein CD66c, validated for a variety of different IAV isolates [12]. We now report $\mathrm{CD} 66 \mathrm{c}$ as the first glycoprotein receptor candidate for IAV entry into host cells. CD66c aka Carcinoembryonic Cell Adhesion Molecule 6 (CEACAM6) is a GPIanchored, raft associated, highly sialylated membrane glycoprotein of the immunoglobulin superfamily (IgSF).

To systematically validate CD66c as a receptor, we overexpressed this molecule on the surface of human lung cells and studied IAV binding and entry. Cells overexpressing CD66c on cell surface showed an increase in virus binding and subsequently increased entry into cells. Besides lung cell line (A549), the effect of CD66c on virus entry was further tested in mouse fibroblasts cells (NIH3T3), Chinese hamster ovary cells (Lec2 CHO) and human embryonic kidney cells (HEK293). On the contrary, when CD66c expression levels were reduced by siRNA-mediated knockdown, we observed a significant decrease in viral binding and entry into lung cells. To further investigate the role of interaction, between viral NA and host CD66c at the cell-surface in virus entry, we performed an antibodymediated receptor-blockade experiment. For this experiment, surface receptor CD66c was masked by incubating a monolayer of A549 lung cells with anti-CD66c monoclonal antibody $(\mathrm{mAb})$ prior to virus binding to this monolayer. Masking of receptor CD66c by the antibody inhibited virus entry probably due to a restricted interaction between the viral spike NA and putative receptor CD66c. Having validated CD66c as a receptor for IAV, it was important to compare the binding capacity of $\mathrm{CD} 66 \mathrm{c}$, towards virus binding and 
entry, with respect to other host glycoproteins (EGFR, DC-SIGN) that had been reported to facilitate virus binding and entry $[7,10]$. We noticed, a significant increase in virus binding and entry into lung cells overexpressing CD66c; however, cells overexpressing EGFR, DC-SIGN showed a modest increase in virus binding and entry, under similar experimental conditions. We also found that overexpression of CD66c did not affect the expression levels of EGFR, DC-SIGN and vice versa. Additionally, we carried out an important experiment to validate $\mathrm{CD} 66 \mathrm{c}$ as a specific receptor for the influenza virus. While glycoprotein CD66c was found necessary for the uptake of influenza virus by cells, it did not affect the entry of another non-IAV RNA virus (Hepatitis $C$ virus). Finally, to confirm our hypothesis, we pre-incubated IAV particles with biologically active human recombinant CD66c protein (expressed in mouse myeloma cell line) prior to infecting BALB/c mice. Interestingly, we observed a significant decrease in infection and cytopathic effects in mice lungs presumably due to masking of the NA spike protein with rCD66c protein.

This study on the identification of CD66c as a receptor for the influenza A virus has potential to further our knowledge on the mechanism of virus entry. Additionally, this newfound receptor brings to attention a new target for anti-viral interventions. CD66c is expressed in epithelium of various tissues and is most abundant in lung epithelia. Since CD66c is an active immunomodulatory molecule (present on T cells, B cells and neutrophils) this finding may also lead to exploration of early immunomodulatory events associated with the interaction between viral NA and CD66c. Influenza neuraminidase is known for playing key roles during assembly and budding of viruses; here we are reporting its new role in virus entry.

\section{Materials and Methods}

\subsection{Plasmid Constructs, Antibodies, Virus Strains, and Mammalian Cell Lines}

$\mathrm{pRc} / \mathrm{CMV}$ plasmid with full-length untagged CD66c gene was used for expression in mammalian cell lines. Human CLEC4M/DC-SIGNR/CD299 gene cDNA ORF clone (cat. HC00654) was purchased from ACROBiosystem Co. LTD. EGFR-GFP plasmid (in EGFP clontech vector backbone) was gifted by Professor Maddy Parson, King's College London. Monoclonal anti-CD66c antibody (mAb anti-CD66c) was purchased from Santa Cruz Biotechnology, Santa Cruz, CA (Catalog \# sc-59899) and anti-NA ( $\alpha$ NA) antibody was purchased from Meridian Life Sciences (Saco, ME). Secondary antibody anti-mouse Alexa Fluor $^{\circledR} 594$ was used against mAb anti-CD66c and anti-rabbit Alexa Fluor ${ }^{\circledR} 488$ against $\alpha$ NA. Anti-CD209/CD299 (DC-SIGN/L-SIGN) was purchased from BioLegend San Diego, CA, USA. A/Puerto Rico/8/34 (PR8) influenza virus strain was used for virus infection experiments both in mammalian cell lines and mice. For detection of viral M1 protein, in-house raised antisera against M1 VLP were used [13]. For detection of NP in flow cytometry and confocal experiments FITC conjugated anti-NP from abcam ${ }^{\circledR}$ Cambridge, MA, USA, was used (Catalog \# ab20921). Influenza virus NP protein was detected using rabbit antisera raised against purified and disrupted PR8 virus [14], which was a kind gift from Dr. Balaji Manicassamy (UIC, Chicago). Virus was used at multiplicity of infection (MOI) of 1 unless specified. Cell lines such as human lung adenocarcinoma epithelial (A549) and NIH3T3 mouse embryonic fibroblast, were purchased from ATCC Manassas, VA, USA. Lec2 $\mathrm{CHO}$ cell line was gifted by Dr. S. Gopalan Sampath Kumar, National Institute of Immunology, New Delhi. Experiments related to human hepatoma cell line, Huh7.5 and JFH-1 infectious HCV were conducted in Dr. Waris's lab. For biochemical experiments in BALB/c mice we used purified recombinant CD66c, expressed in mouse myeloma cell line, purchased from R\&D systems Minneapolis, MN, USA (Catalog \# 3934-CM, activity checked by the manufacturer).

\subsection{RNA Interference and Virus Infection Experiments}

Mock-infected and PR8-infected A549 and Huh 7.5 cells were transfected with CD66c siRNA according to the manufacturer's protocols (Santa Cruz Biotechnology Dallas, TX, USA). A concentration of $30 \mathrm{nM}$ of siRNA was used. The Huh 7.5 cells treated with Si-RNA 
were cultured into 6 well plates for $48 \mathrm{~h}$ then either left uninfected or infected with 0.5 MOI of HCV in the incomplete Dulbecco's Modified Eagle's Medium (DMEM, Thermo Fisher Scientific, Waltham, MA, USA) medium for $5 \mathrm{~h}$, then replaced with complete DMEM medium, followed by incubation for $48 \mathrm{~h}$ in the $5 \% \mathrm{CO}_{2}$ incubator at $37{ }^{\circ} \mathrm{C}$. Similarly, A549 cells were infected with the PR8 virus but with different MOI (1-5), MOI 1 for virus infection level detection and MOI 5 for the virus binding experiments (also specified in legends to figures).

\subsection{Antibody Mediated Receptor Blockade Experiments and Influenza Binding, Infection to the Cells}

Cells (A549 and NIH3T3) were plated at a density of 106/well in a 6-well culture plate. The cell monolayers were washed with PBS three times and incubated either with anti-CD66c mAb or with IgG1 isotype antibody, in $200 \mu \mathrm{L}$ of PBS with $3 \%$ fetal calf serum (FCS) for $40 \mathrm{~min}$ at $20^{\circ} \mathrm{C}$. Unbound antibody was removed by washing cells with PBS following which cell monolayer was incubated with PR8 virus in OPTI-MEM (3\% FCS) for $1 \mathrm{~h}$ at $37{ }^{\circ} \mathrm{C}$ under $5 \% \mathrm{CO}_{2}$. Specifically, for virus binding experiments, cell monolayers were washed with PBS three times; following this, PR8 virus aliquots at the 1 to $5 \mathrm{MOI}$ was prepared in $200 \mu \mathrm{L}$ of OPTI-MEM (3\% FCS) and incubated for the duration of 1 min to $1 \mathrm{~h}$ as per the objective of experiments. Unbound virus was washed with PBS thrice and cells were fixed immediately for FACS and IFA staining (without permeabilization). The medium was replaced with DMEM (10\% FCS) and cells were incubated at $37{ }^{\circ} \mathrm{C}$ under $5 \%$ $\mathrm{CO}_{2}$. Cells were harvested for time points of $8 \mathrm{HPI}$ or $24 \mathrm{HPI}$. The extent of viral infection in cells was determined by probing viral proteins (M1 and NP) through flow cytometry and western blot analysis.

\subsection{Immunofluorescence Microscopy}

Intracellular and extracellular immuno-staining of cells were performed during this study. For intracellular staining, cell monolayer, that was fixed by overlaying $4 \%$ paraformaldehyde, was permeabilized by treating with PBS containing $0.5 \%$ Triton X-100 for $10 \mathrm{~min}$ at $37^{\circ} \mathrm{C}$. Following this, the cell monolayer was conditioned and blocked with Phosphate-buffered saline (PBS) containing 0.5\% Triton X-100 and 0.5\% (wt/vol) Bovine serum albumin (BSA) for $1 \mathrm{~h}$. Permeabilized cells were incubated with FITC-conjugated primary antibody against viral NP at a dilution of 1:200 in antibody solution (PBS containing $0.5 \%$ Triton $\mathrm{X}-100,0.1 \%$ [wt/vol] sodium azide and $0.5 \%$ [wt/vol] BSA) for $30 \mathrm{~min}$. This was followed by washing cells with PBS containing $0.5 \%$ Triton X-100 to remove excess antibodies and mounting cells on slides for observation under confocal microscope (A1R; Nikon, Tokyo, Japan). Extracellular staining was a two-step process, wherein cells fixed in $4 \%$ paraformaldehyde were incubated with primary antibody (anti-CD66c or anti-NA) followed by respective fluorescent secondary antibodies, bypassing the cell permeabilization step. Primary antibody was used at dilution of 1:100 and secondary antibodies were used at a dilution ratio of 1:1000 in antibody solution.

\subsection{Flow Cytometric Analysis}

For intracellular Influenza NP staining, viral infected cells were washed with PBS and centrifuged to remove debris. Single cell suspension thus formed was fixed with $4 \%$ paraformaldehyde (PFA) in PBS. Fixed cells were then washed twice with PBS containing $3 \%$ FCS and resuspended in a permeabilization buffer (Cytofix/Cytoperm kit; BD, Franklin Lakes, NJ, USA) for $10 \mathrm{~min}$. The permeabilized cells were incubated for $45 \mathrm{~min}$ with Fluorescein isothiocyanate (FITC) conjugated NP antibody (primary) in PBS (with 3\% FCS). The stained cells were washed with buffer (3\% FCS in PBS) to remove unbound antibody and taken for cytometric readings. For extracellular staining of CD66c or the viral NA attached to cells during virus binding experiments, we performed standard extracellular staining protocol bypassing the cell permeabilization step. Cells with or without virus on their surface were fixed with $4 \%$ PFA in PBS, followed by washing with PBS. Fixed cells or cell-virus complex were then incubated with anti-CD66c primary monoclonal antibody 
or anti-NA primary antibody in $50 \mu \mathrm{L}$ of PBS with $3 \%$ FCS for 40 min at $4{ }^{\circ} \mathrm{C}$ (antibodies to solution ratio was 1:200). After washing unbound antibody cells were incubated with secondary antibody against these primary antibodies (anti-CD66c, anti-NA) in 50 $\mu \mathrm{L}$ of PBS with $3 \%$ FCS for $40 \mathrm{~min}$ at $4{ }^{\circ} \mathrm{C}$. Ratio of secondary antibodies to solution was 1:1000 (v/v). After washing unbound secondary antibodies to cells in PBS with 3\% FCS, stained cells were taken for cytometric analysis. Fluorescence intensity was measured by flow cytometry (FACS Calibur; BD, Franklin Lakes, NJ, USA) and data was analyzed using FlowJo (BD, Franklin Lakes, NJ, USA).

\subsection{Semi Quantitative and Real-Time PCR}

Total RNA from cells was extracted using RNeasy Mini Kit (Qiagen, Germantown, MD, USA) and treated with DNase I (Invitrogen, Waltham, MA, USA). $2 \mu \mathrm{g}$ of RNA was reverse-transcribed using M-MLV Reverse Transcriptase (ThermoFisher, Waltham, MA, USA, Catalog \# 28025013) at a volume of $20 \mu \mathrm{L}$. The synthesized cDNA was diluted 1:5 in water. $2.0 \mu \mathrm{L}$ of cDNA was then used in a SYBR ${ }^{\circledR}$ Green PCR Master Mix (Applied Biosystems, Waltham, MA, USA) based real-time PCR reactions at a volume of $20 \mu \mathrm{L}$. StepOneTM PCR machine was used to acquire real-time PCR readouts.

Primer sequence: the following primer sequences were used for the semi quantitative and Real-Time PCR reactions.

NP forward CTGATGGAGAACGCCAGAAT; NP reverse TTCGTCAAAAGCAGAGAGCA.

M1 forward CGAGATCGCACAGAGACTTG; M1 reverse TTC CCA TTA AGGGCATTTTG; ARPP P0 forward GCACTGGAAGTCCAACTACTTC; ARPP P0 reverse TGAGGTCCTCCTTGGTGAACAC.

\subsection{Incubation of Virus with Recombinant Protein, Intranasal Challenge of Mice and Lung Histology}

$1 \mu \mathrm{g}$ of recombinant CD66c protein was incubated with $50 \mu \mathrm{L}$ of PR8 virus in PBS, with a titer of $1.48 \times 109 \mathrm{pfu} / \mathrm{mL}$, for $30 \mathrm{~min}$ so that protein binds with the virus. Six-weekold female BALB/c mice were first anaesthetized with isoflurane, and were inoculated with $50 \mu \mathrm{L}$ of virus (incubated with recombinant CD66c) in PBS intranasally. Mock mice group were inoculated with $50 \mathrm{~mL}$ of virus pre-incubated with BSA as a protein control. A group of mice was also inoculated with untreated PR8 virus (virus without any protein incubation). Survival and the body weight of the mice were monitored regularly for 10 days post infection. Mice were then euthanized and lungs were taken out for study. Lung tissues were preserved in formalin embedded in paraffin and were cut in uniform 4$\mu \mathrm{m}$ sections. Tissue sections were stained with hematoxylin and eosin stain and examined for histopathological changes under the microscope at $20 \times$ magnification.

\section{Results}

3.1. Characterization of Role of CD66c in Infection

3.1.1. Overexpression of CD66c on Human Lung Cell Surface Resulted in Increased Virus Binding

The physical interaction between influenza NA and CD66c of virus-infected cells was confirmed earlier by co-immunoprecipitation assays [12]. Here, we performed experiments to quantify virus binding on the surface of cells overexpressing CD66c glycoproteins. A549 lung cells transiently transfected with untagged CD66c gene showed a rise in the expression of this molecule at the host cell surface when monitored by flow cytometry (Figure 1a). Further, lung cells overexpressing CD66c showed significantly increased virus binding on cell surface. Increase in virus binding was detected by quantitatively probing NA on the host cell surface. Our results showed an increase in viral NA on the surface of CD66c overexpressing cells, indicating higher virus binding (Figure 1b). Flow cytometry results showed that among cells with endogenous level of CD66c, $18 \%$ of the total cell population had virus bound to cell surface. In contrast, CD66c overexpressing cells showed that approximately $80 \%$ of total cell population had virus bound to the cell surface (Figure $1 \mathrm{~b}$ ). 
We further carried out experiments to investigate whether the NA present on the virus surface colocalized with the putative receptor CD66c. For this experiment, we let IAV bind over a monolayer of human lung cells and subsequently stained cells with a mixture of two antibodies, anti-NA and anti-CD66c. Confocal microscopy revealed colocalization of CD66c with viral NA at the cell surface (Figure 1c). The CD66c (red) and viral NA (green) bound to the cell surface were clearly visible on merged view (yellow) (Figure 1c). The interaction of overexpressed CD66c and NA in cells transfected with respective plasmids was reported in the previous study [12].

\section{(a)}

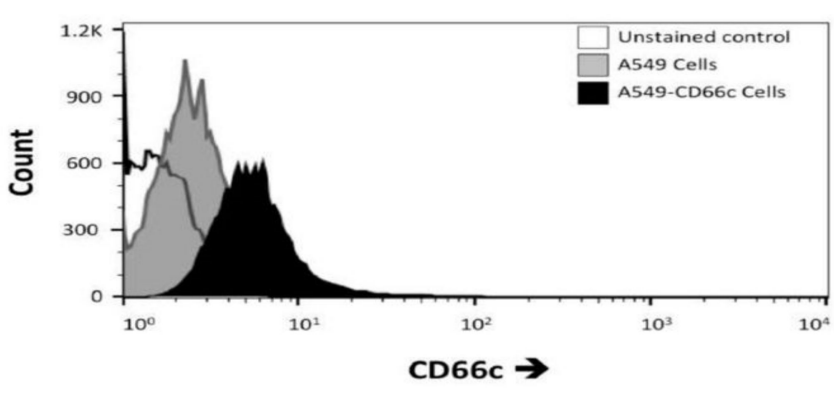

(b)

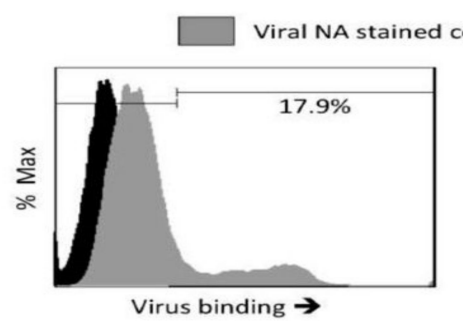

A549 Cells with endogenous CD66c

(c)
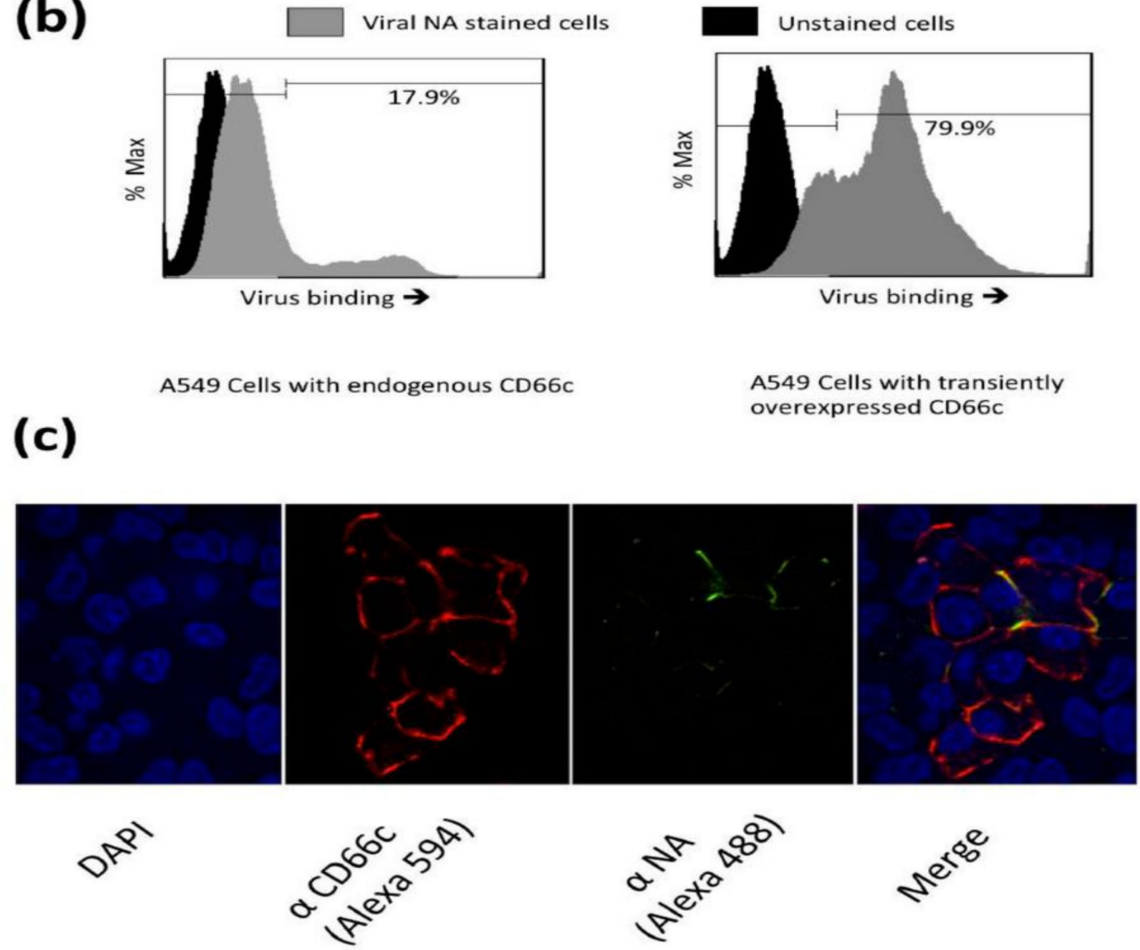

Figure 1. (a): Flow cytometry analysis of surface expression of CD66c in A549 cells. Cell population transiently overexpressing CD66c shows signal for higher expression of CD66c on the cell surface (black) as compared to A549 cells (grey), unstained control cells (white). (b): Flow cytometry analysis of virus binding on A549 cells or CD66c overexpressing A549 cells. 5 multiplicity of infection (MOI) of PR8 virus binding signal corresponding to stained NA protein (Alexa-488) of the virus on host cell surface. Signal of unstained cells (black), viral NA (grey) corresponding to the virus binding on cell surface. PR8 virus binding is increased from $~ 18 \%$ (left panel) to $>80 \%$ of CD66c overexpressing A549 cell population (right panel). (c): To a monolayer of A549 cells, binding of 5 multiplicity of infection (moi) of PR8 virus was observed under confocal microscope. Panels from left to right shows cell nuclei stained with DAPI (blue), CD66c (red), Viral NA (green) at the cell periphery. Colocalization (yellow) of NA protein of PR8 virus (green) with host membrane protein CD66c (red) at the periphery of cells. 


\subsubsection{Cells Overexpressing CD66c Showed Increased Virus Entry}

We further sought to determine if CD66c overexpression in host cells increased virus entry. We quantified mRNA levels of viral NP and M1 after harvesting PR8 infected A549 lung cells, approximately $8 \mathrm{~h}$ post-infection, h.p.i (one life cycle). Cells overexpressing CD66c showed a 6-8 fold increase in the levels of M1 and NP mRNA (Figure 2a,b). We also measured viral NP protein in CD66c expressing A549 cells that showed 7-fold increase in its expression levels (Figure 2c-f). To demonstrate that the NA-CD66c interaction also affected virus entry in other types of cell, we performed similar experiments using the mouse embryonic fibroblast cell line NIH3T3. CD66c expressing NIH3T3 cells (NIH3T3-CD66c cells) showed an increase in NP mRNA levels as against the NIH3T3 cells (Figure 3a). Likewise, we checked the virus binding and entry in CD66c overexpressing Lec2 $\mathrm{CHO}$ cell lines. Lec $2 \mathrm{CHO}$ cell lines transiently overexpressing CD66c favored virus binding on cell surface and subsequent uptake of the virus into cells (Figure $3 b, c)$. HEK cells overexpressing CD66c cells showed increase in virus entry, which was monitored by an increase in the NP mRNA levels (Figure 3d).

3.1.3. siRNA Knockdown of CD66c Inhibited Virus Binding on Cell Surface and Subsequent Entry into Lung Cells

After having conducted overexpression studies with CD66c, we carried out siRNA experiments to silence the expression of this molecule and subsequently studied virus binding and entry into lung epithelial cells. For virus binding experiments cells incubated with virus for a brief period of $5 \mathrm{~min}$ were stained extracellularly for receptor CD66c (green) and Neuraminidase (red) and observed under fluorescent microscope. We found that siRNA mediated knockdown of CD66c expression in A549 lung cells resulted in the inhibition of virus binding on the cell surface (Figure 4). Cells treated with CD66c siRNA showed poor expression of CD66c as shown by a weak green signal in uninfected cells (UI) and 5 min post-infected cells $\left(5^{\prime}\right)$, as against control siRNA treated cells (Figure 4). Virus binding was not observed on the surface of cells silenced for CD66c, as observed by a reduced red signal for neuraminidase (lower two panels, Figure 4). In contrast, mock siRNA treated cells showed significant endogenous expression levels of CD66c (green) both in viral infected $\left(5^{\prime}\right)$ and uninfected cells (UI). As expected, these cells upon infection showed significant viral binding on the cell surface, which was probed by viral NA (red). Accordingly, these cells showed significant colocalization of NA (red) with CD66c (green) in merged fields (yellow) (Figure 4). Altogether, we observed that cells with endogenous level of CD66c showed significant virus binding at the cell surface; however, cells silenced for CD66c did not show any visible virus binding on the cell surface due to absence of surface receptor CD66c (Figure 4). To validate our immunofluorescence assay (IFA) data we performed a western blot analysis to study the effect of siRNA-mediated-silencing of CD66c in virus entry (Figure 5). The siRNA treated lung cells that showed complete loss of CD66c expression consequently demonstrated inhibition of viral infection as was evident from poor expression of the viral protein NP (Figure 5). Additionally, using western blot analysis, effect of CD66c silencing on expression levels of membrane protein EGFR and DC-SIGN were evaluated. We found that siRNA mediated silencing of CD66c did not suppress the expression of EGFR and DC-SIGN (Figure 5). More importantly this data also suggested that expression of CD66c in A549 lung cells did not have any effect on the expression levels of EGFR and DC-SIGN. 
(a)

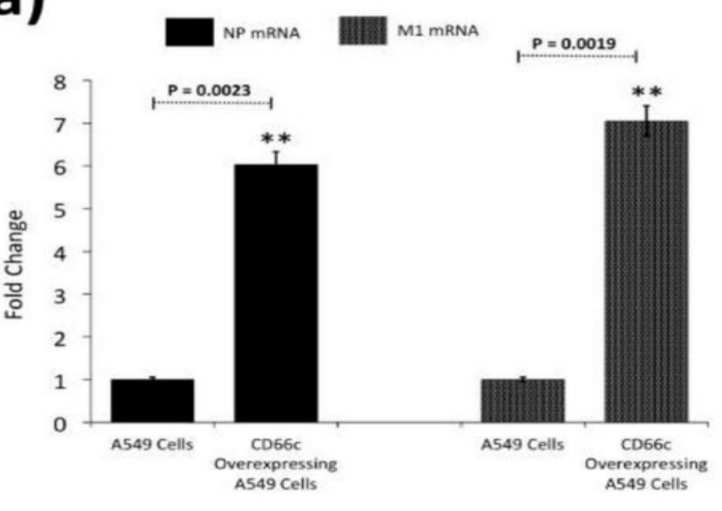

(c)

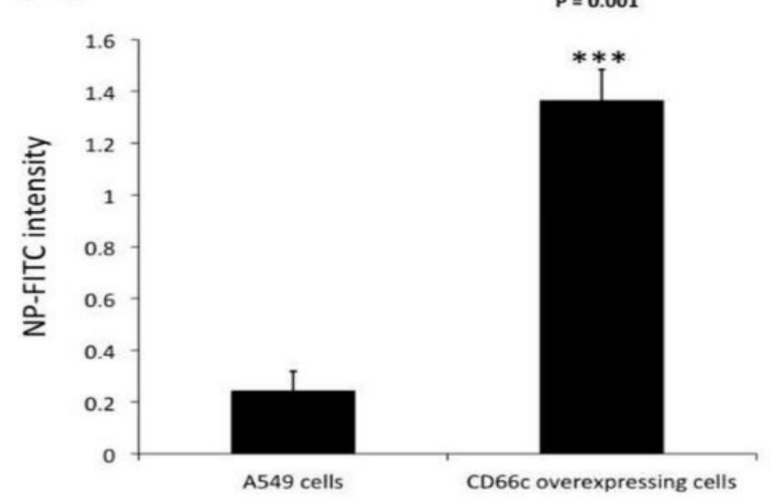

(e)

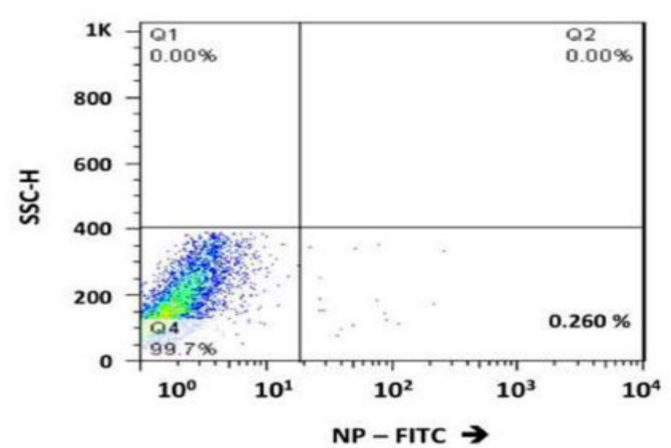

(b)

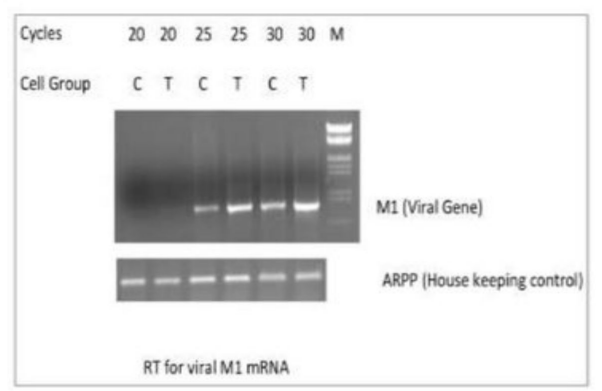

(d)

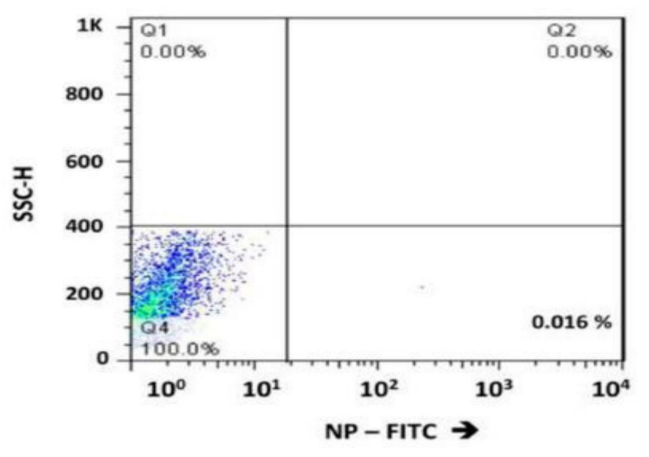

(f)

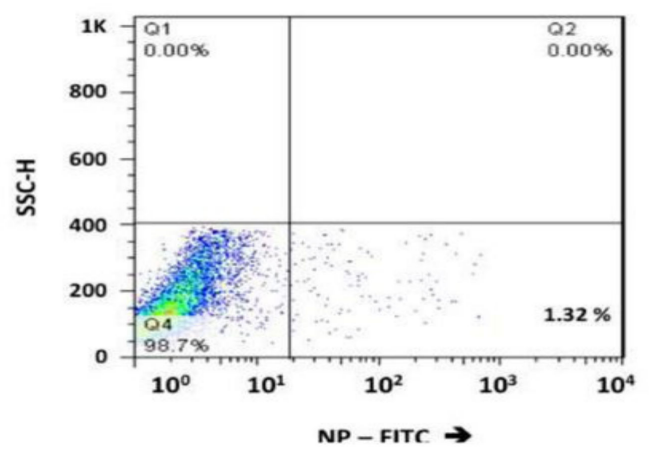

Figure 2. (a): Real time quantification of NP and M1 mRNA in viral infected A549 cells 8 h post infection ( 8 h.p.i) infected cells. Figure shows higher mRNA levels of NP (left two bars) and M1 (right two bars) in cells overexpressing CD66c. Each bar represents mean of five independent experimental readings. (b): Semi quantification of viral M1 by RT-PCR. For the above-mentioned reaction condition (8 h.p.i, and 1) viral M1 mRNA was also measured semi-quantitatively. Before each lane A549 control cells is denoted as " $\mathrm{C}$ ", or A549 cells having overexpressed CD66c with "T". Cycles are the number of PCR cycles. (c): Flow cytometric analysis for virus load in A549 infected cell: The bar diagram shows rise in viral NP in CD66c overexpressing A549 cells (right) than that in A549 cells (left). Each bar represents mean values of at least three independent experiments \pm SD. Statistical significance was assessed by student's $t$-test, $\left({ }^{* *}\right)$ for $p \leq 0.01$ and $\left({ }^{* * *}\right)$ for $p \leq 0.001$. (d): Representative FACS snapshot of unstained A549 cells showing no signal corresponding to NP-FITC in lower-right quadrant; cells with some signal in (e); cells overexpressing CD66c with increased NP-FITC signal in lower-right quadrant (f). 
(a)

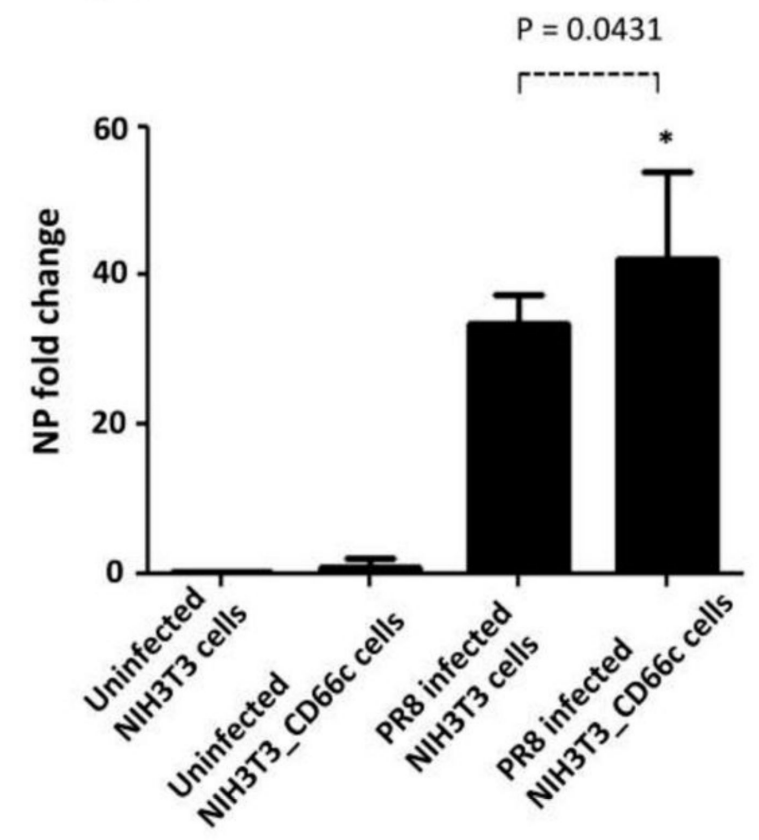

(c)

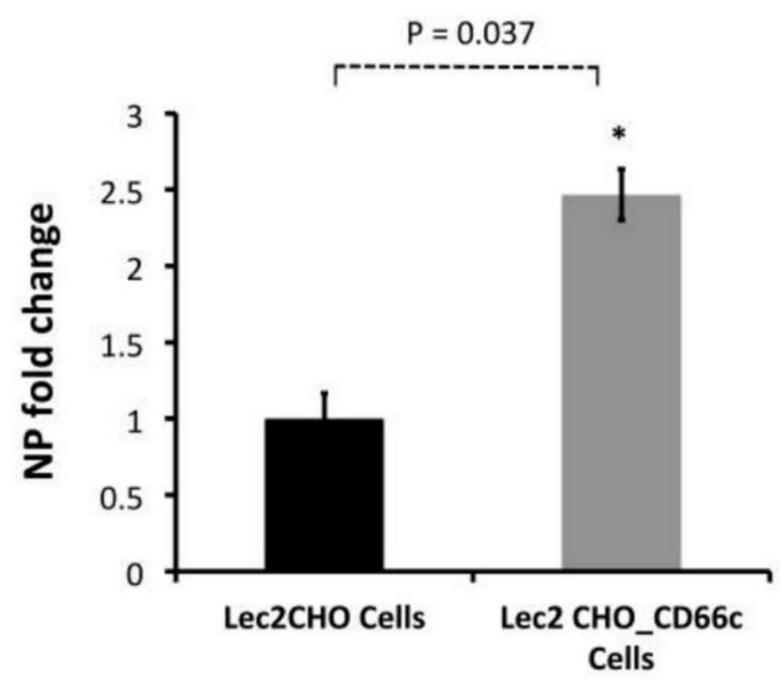

(b)

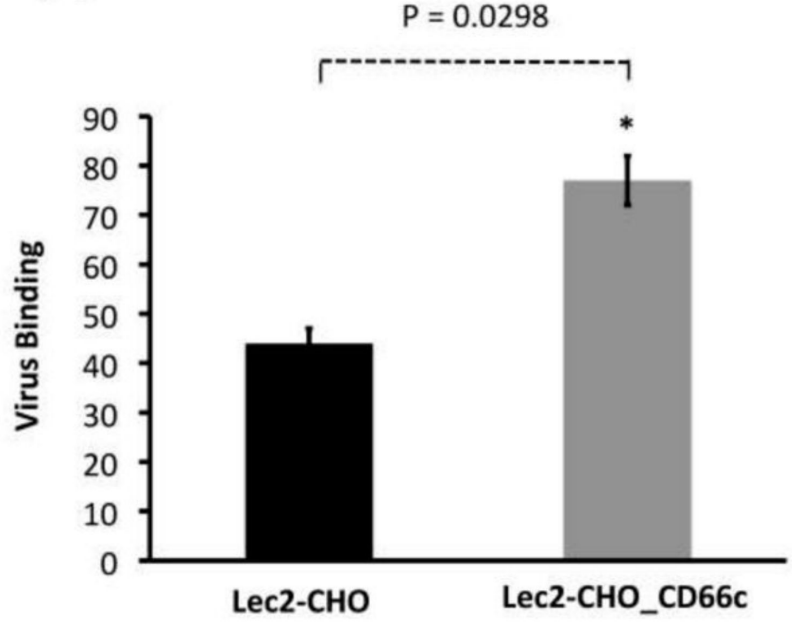

(d)

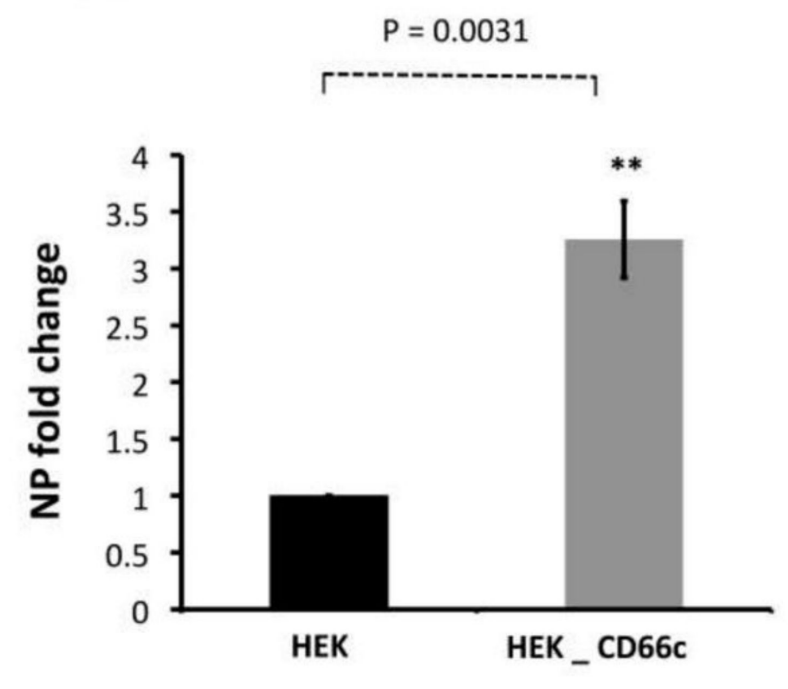

Figure 3. Demonstration of rise in viral uptake in CD66c overexpressing NIH 3T3 and Lec2-CHO cell lines. (a): The level of infection as probed by the NP mRNA fold-change. The bar in the right end shows increased influenza infection in CD66c transfected NIH3T3 cell lines. (b): Lec2 CHO-CD66c is CD66c overexpressing Lec2 CHO cell lines. The right bar shows greater virus binding on the surface of cells overexpressing CD66c. (c): An increased level of viral NP mRNA in Lec2 $\mathrm{CHO}-\mathrm{CD} 66 \mathrm{c}$ cells (right bar) as compared to Lec2 $\mathrm{CHO}$ cells (left bar) suggesting increased virus entry. (d): Levels of mRNA corresponding to lower infection level in HEK cells (left bar) and an increase in infection in CD66c overexpressing HEK cells (right bar). Statistical significance was assessed by student's $t$-test, ${ }^{*}$ ) for $p \leq 0.05$ and $\left(^{* *}\right)$ for $p \leq 0.01$. 


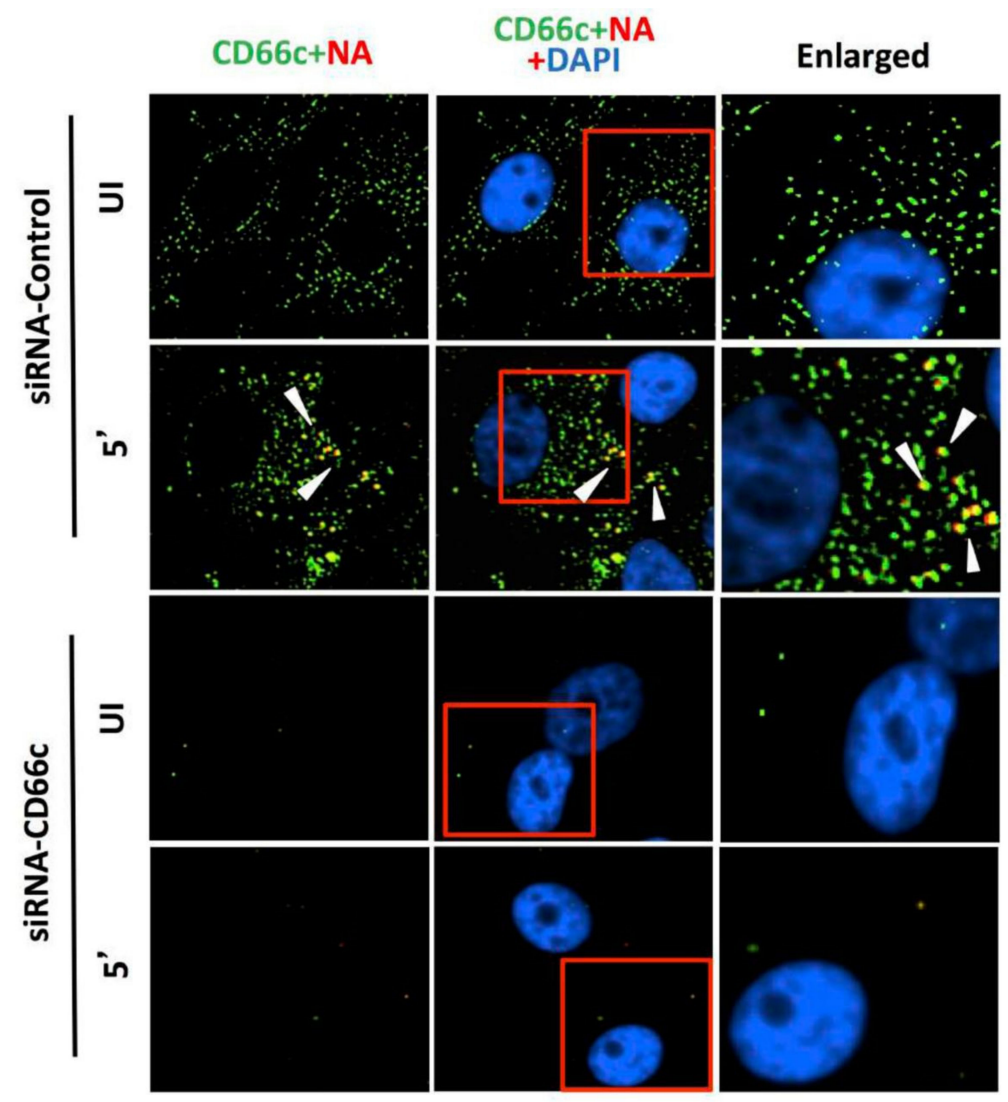

Figure 4. Knockdown of CD66c shows inhibition of virus binding on cell surface under fluorescent microscope. Here, UI denotes uninfected cells; $5^{\prime}$, Cells after 5 min of virus binding to them. Figure shows that A549 cells treated with siRNA control (negative) do not inhibit expression level of CD66c (green) and therefore binding of 5 multiplicity of infection (MOI) of PR8 viruses on cell surface can be seen. Figure shows colocalization between NA (red) and CD66c (green) in merged view (yellow) (second panel from top, pointed with white arrow). Amount of colocalization between NA and CD66c and absence of NA (red color) in control siRNA treated cells signifies possible colocalization between CD66c and NA at the host cell surface. The lowest two panels show diminished green signals in cells treated with CD66c siRNA suggesting a poor expression of CD66c protein (green). Consequently, virus binding on siRNA-CD66c treated cells is not seen, as evident by the absence of any green (CD66c) or red (NA) signal (bottom panel).

3.1.4. Antibody-Mediated Masking of Receptor CD66c at Cell Surface Inhibited Virus Entry

From our previous publication, it was established that NA interacts with CD66c inside the host cell and overexpression of CD66c influenced cell survival pathways (PI3K-Akt), with subsequent increase in viral load in infected cells [12]. In this context, a decrease in viral load in cells knocked down for CD66c (Figure 4) may be implicated due to a corresponding down modulation of cell survival pathway (PI3K-Akt). Therefore, this result (Figure 4) is not sufficient to claim that CD66c is a receptor. To validate that CD66c is a receptor for viral entry, we need evidence to demonstrate the effect of direct interaction, between CD66c and NA at the host cell surface, in virus entry. Therefore, we conducted the receptor-blockade experiment, demonstrating that a disruption of physical interaction between host CD66c and viral NA at the cell surface could affect viral entry. Initially, we performed antibody-mediated receptor blockade experiments on CD66c overexpressing NIH3T3 (NIH3T3-CD66c) cells. For this experiment, a monolayer of NIH3T3-CD66c cells when treated with $\mathrm{mAb}$ anti-CD66c at increasing concentrations of $1.0 \mu \mathrm{g} / \mathrm{mL}, 1.5$ $\mu \mathrm{g} / \mathrm{mL}, 2.0 \mu \mathrm{g} / \mathrm{mL}$ and $8.0 \mu \mathrm{g} / \mathrm{mL}$, preceding virus infection. This experiment revealed significant decrease in virus infection in a dose dependent manner. The virus entry levels 
in these cells were determined by the mRNA levels of viral NP (Figure 6a). Likewise, inhibition of virus entry was observed by determining expression levels of viral NP protein in NIH3T3-CD66c cells, when treated with increasing concentrations of anti-CD66c mAb prior to infection (Figure 6b). From these results, lower levels of NP (mRNA and protein) in anti-CD66c mAb treated cells suggested that masking of CD66c on host cell surface by $\mathrm{mAb}$ reduced its access to NA spike protein present on the surface of the infecting virus particles, thus inhibiting virus binding and uptake. For conclusive validation of our hypothesis, we finally performed $\mathrm{mAb}$ mediated receptor blockade experiment in A549 lung cells with endogenous (not overexpressed) levels of CD66c on the cell surface. In a control experiment we also tested the effect of mock antibody (IgG isotype) binding on the A549 cell monolayer as against CD66c binding (Figure 7a,b), as the experiment control for specific monoclonal antibody binding. We observed a corresponding decrease in virus entry when cells were treated with $\mathrm{mAb}$ anti-CD66c at the respective concentrations of $1.0 \mu \mathrm{g} / \mathrm{mL}, 1.5 \mu \mathrm{g} / \mathrm{mL}, 2.0 \mu \mathrm{g} / \mathrm{mL}, 4.0 \mu \mathrm{g} / \mathrm{mL}$ and $8.0 \mu \mathrm{g} / \mathrm{mL}$ (Figure $7 \mathrm{c}$ ). Inhibition of virus entry was demonstrated by measuring a corresponding reduction in expression levels of viral NP protein in infected cells by flow cytometry (Figure $7 \mathrm{~d}-\mathrm{g}$ ). The dose dependence of $\mathrm{mAb}$ anti-CD66c in the inhibition of viral entry was also confirmed by quantitating another viral protein, M1 in the corresponding cells (Figure 7h,i). One set of the antibody mediated receptor blockade experiment was also studied under confocal microscopy, which showed similar inhibition of virus entry into A549 cells that were treated with $4.0 \mu \mathrm{g} / \mathrm{mL}$ of anti-CD66c mAb (Figure 7j).

\section{A549 cells (Whole cell lysate)}

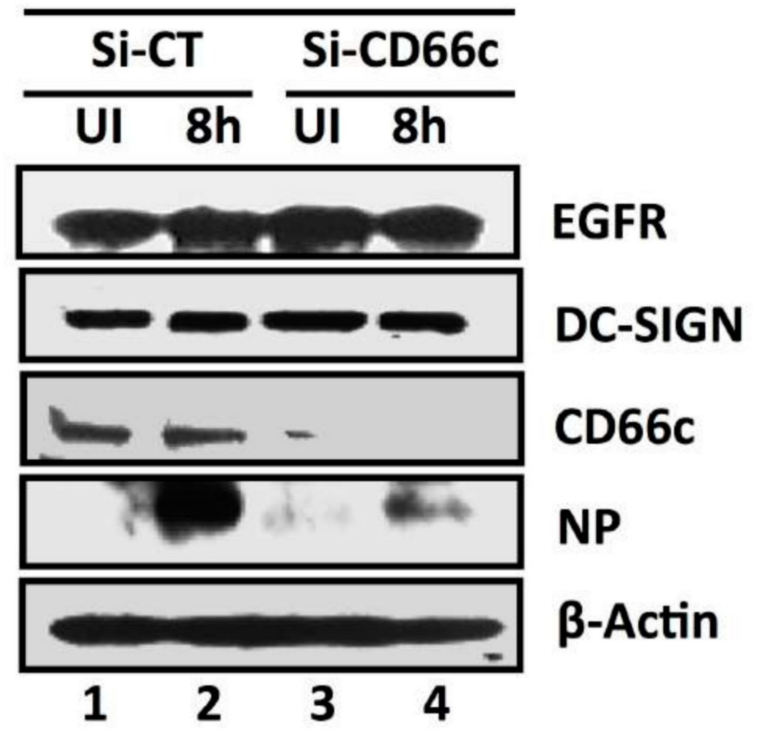

Figure 5. siRNA-mediated knockdown of CD66c shows inhibition of virus entry into lung-cells infected with $1 \mathrm{MOI}$ of PR8 virus, through western blot analysis. Here, Si-CT denotes control siRNA treated cells; Si-CD66c are cells treated with CD66c siRNA. 8h are cells harvested after $8 \mathrm{~h}$ of infection (one life cycle of IAV), UI are uninfected cells. A549 cells treated with siRNA show complete knock down of the receptor molecule CD66c (third panel from top) while control siRNA treated cells do not show any reduction in expression of CD66c (left two wells of third panel). The fourth panel from top shows level of A/PR8/34 influenza virus entry in cells determined by expression levels of viral NP protein. The second well from left shows significant expression level of viral NP protein in cells treated with control siRNA, eight hours after infection. In contrast, the right-most well shows a marked reduction of influenza A virus (IAV) entry in cells treated with CD66c siRNA, as determined by low expression level of viral protein NP eight hours after infection. Conclusively, virus entry was inhibited in absence of CD66c (CD66c siRNA treated cells). CD66c siRNA treated cells do not show any noticeable change in expression levels of EGRF (topmost panel) and DC-SIGN (second panel from top). For loading control $\beta$-Actin was probed (the bottom panel). 
(a)

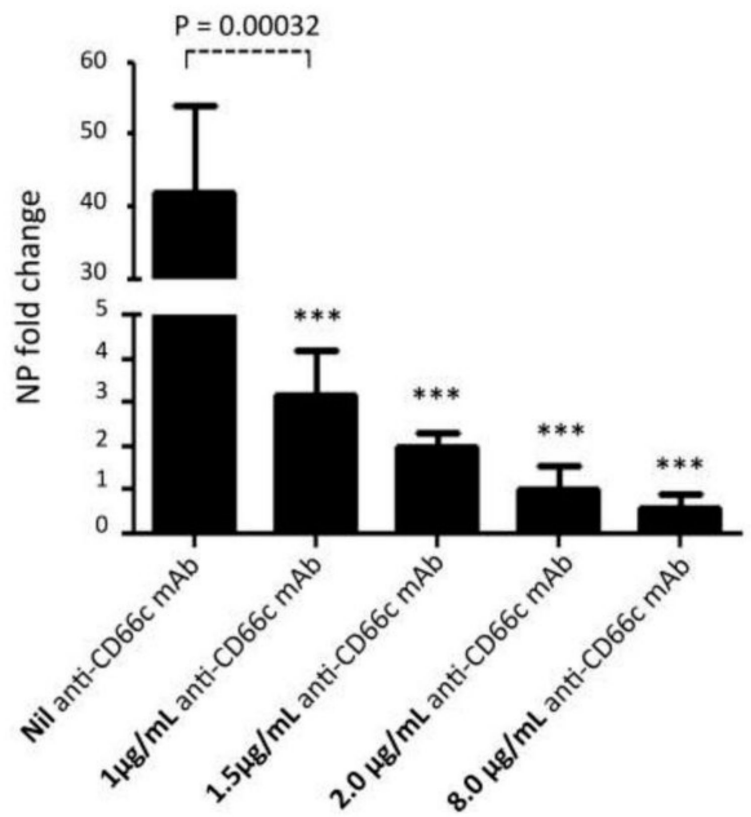

(b)

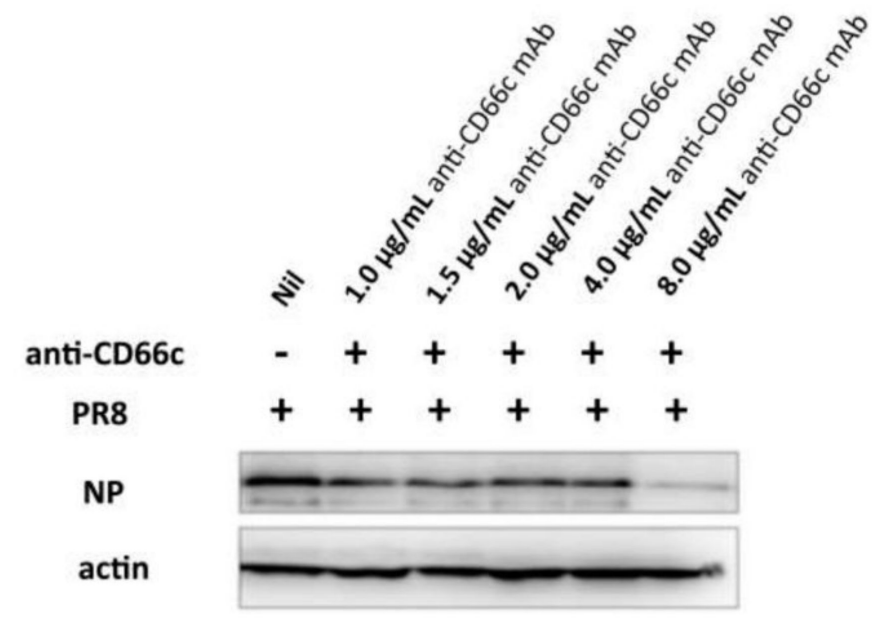

Figure 6. Antibody mediated receptor blockade experiments in CD66c overexpressing cells. (a): The figure shows level of A/PR8/34 influenza virus entry in a monolayer of NIH3T3-CD66c cells when treated with mAb anti-CD66c prior to infection. From left to right, the first bar in the figure represents levels of viral NP mRNA (a measure of virus entry) in untreated NIH3T3-CD66c. Bars second to fifth from left show levels of viral NP mRNA in virus-infected cells treated with $\mathrm{mAb}$ anti-CD66c at a concentration of $1.0 \mu \mathrm{g} / \mathrm{mL}, 1.5 \mu \mathrm{g} / \mathrm{mL}, 2.0 \mu \mathrm{g} / \mathrm{mL}$ and $8.0 \mu \mathrm{g} / \mathrm{mL}$ respectively. Conclusively, the data show a decrease in virus entry in cells treated with anti-CD66c in a dose dependent manner. Data represent mean values of at least three independent experiments \pm SD. Statistical significance was assessed by student's $t$-test (GraphPad), $\left(^{*}\right)$ for $\left.p \leq 0.05,{ }^{* *}\right)$ for $p \leq 0.01$ and $\left(^{* *}\right)$ for $p \leq 0.001$. (b): A western blot showing expression levels of viral NP protein in virus-infected NIH3T3-CD66c when treated with corresponding concentrations of mAb anti-CD66c $1.0 \mu \mathrm{g} / \mathrm{mL}, 1.5 \mu \mathrm{g} / \mathrm{mL}$, $2.0 \mu \mathrm{g} / \mathrm{mL}, 4.0 \mu \mathrm{g} / \mathrm{mL}$ and $8.0 \mu \mathrm{g} / \mathrm{mL}$, prior to viral infection. The inhibition of virus entry in anti-CD66c mAb treated cells was significant at a concentration of $8.0 \mu \mathrm{g} / \mathrm{mL}$ of CD66c. 
(a)

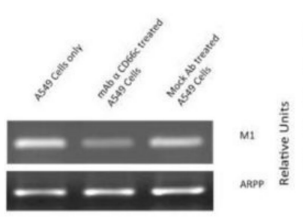

(d)

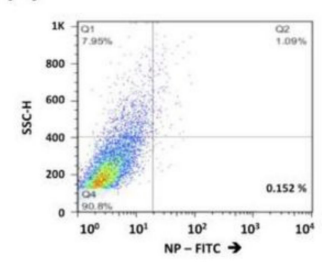

(e)

(b)

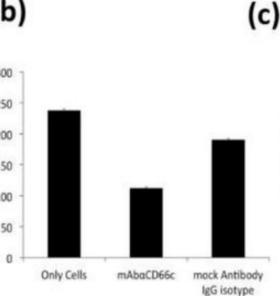

(c)

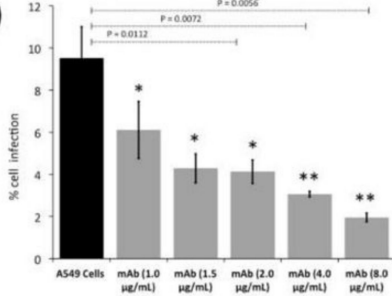

(f)

(g)

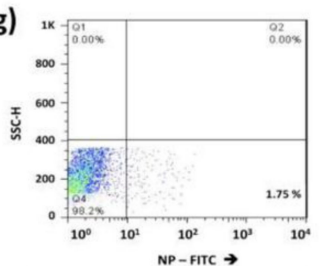

(h)
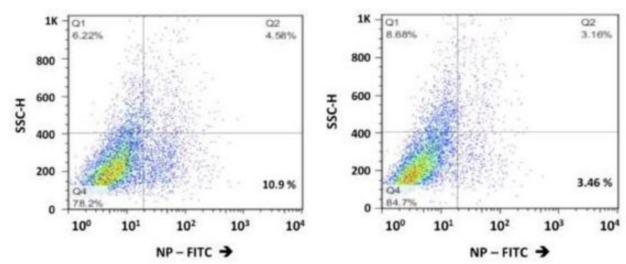

(j)

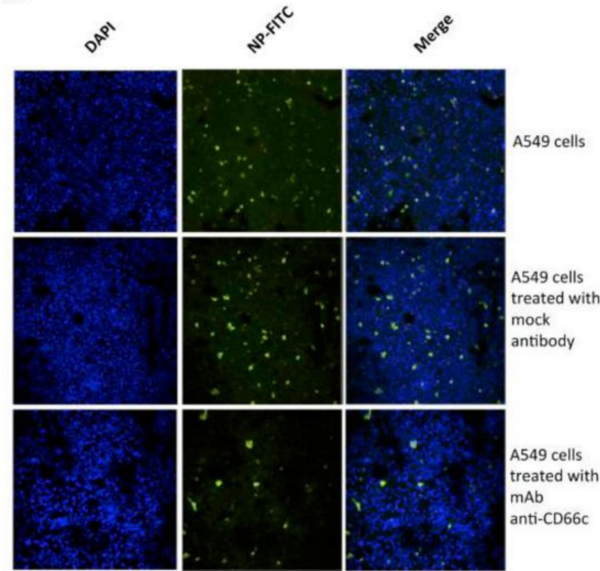

(i)

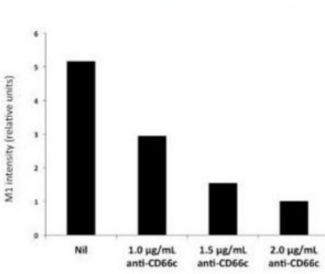

Figure 7. Antibody mediated receptor blockade experiments in A549 cells expressing endogenous levels of CD66c, during A/PR8/34 influenza virus infection in lung A549 cells (24 HPI), when incubated with increasing concentrations of anti-CD66 $\mathrm{mAb}$ prior to infection. (a): Left well shows M1 mRNA level in A549 cells (left) in cells incubated with mAb anti-CD66c (middle) and the right well shows M1 mRNA level in cells incubated with mock antibody (IgG isotype antibody) prior to viral infection. (b): Densitometry analysis of image (a). The expression level of housekeeping gene acidic ribosomal phosphoprotein (ARPP) as experimental control. (c): A549 cells expressing viral NP protein (a measure of virus entry) after infection without any anti-CD66c treatment (black bar). Grey bars (from left to right) represent A549 cells treated with anti-CD66c mAb, prior to infection, at the concentrations of $1.0 \mu \mathrm{g} / \mathrm{mL}, 1.5 \mu \mathrm{g} / \mathrm{mL}, 2 \mu \mathrm{g} / \mathrm{mL}, 4 \mu \mathrm{g} / \mathrm{mL}$ or $8 \mu \mathrm{g} / \mathrm{mL}$, respectively. Each bar shows the mean of three independent experimental readings $\left({ }^{*}, p<0.05 ; * *, p<0.01\right)$. Figures $(\mathbf{d}-\mathbf{g})$ are representative snapshots of NP stained cells from flow cytometry. (d): Unstained A549 cells (e): A549 cells with NP-FITC signal in 10.9\% cell population. (f): A549 cells incubated with $4.0 \mathrm{\mu g} / \mathrm{mL}$ of $\mathrm{mAb}$ anti-CD66c with relatively reduced signal, in 3.46\% cell population. (g): A549 cells incubated with $8.0 \mu \mathrm{g} / \mathrm{mL}$ of mAb anti-CD66c. (h): Western blot analysis of infection in A549 cells incubated with anti-CD66c mAb at a concentration of $1.0 \mu \mathrm{g} / \mathrm{mL}, 1.5 \mu \mathrm{g} / \mathrm{mL}$ or $2.0 \mu \mathrm{g} / \mathrm{mL}$, prior to infection by the virus. (i): Densitometry analysis of (h). (j): Immunofluorescent assay (IFA) and confocal microscopic analysis of A/PR8/34 virus-infected A549 cells at 24 HPI, staining viral NP (green). Uppermost panel shows infection level in A549 cells, the middle panel shows infection in cells incubated with mock antibody (IgG Isotype control) and the bottom panel shows reduced infection in cells incubated with $4 \mu \mathrm{g} / \mathrm{mL}$ anti-CD66c mAb before viral infection. 


\subsubsection{Virus Binding and Entry in Cells Overexpressing CD66c, EGFR and DC-SIGN}

Reports earlier showed that overexpression of two membrane proteins (EGFR and DCSIGN) resulted in an increase in virus binding and entry into mammalian cells. Therefore, we conducted an experiment to compare virus binding and entry in cells overexpressing CD66c, EGFR and DC-SIGN, respectively. For this experiment we checked the extent of virus binding on the lung cells, at the endogenous and overexpressed levels of these host membrane glycoproteins (EGFR, DC-SIGN and CD66c). We reasoned that a genuine receptor upon overexpression in lung cells should exhibit significant increase in virus binding on the cell surface, whereas a weak receptor candidate upon overexpression should display a modest increase in virus binding. After allowing IAV virus to bind to cell monolayers, we examined the cultures under a fluorescence microscope to monitor the membrane glycoproteins (green) and viral NA (red). We did not notice significant increase in virus binding on lung cells overexpressing EGFR as against cells with endogenous levels of EGFR (Figure 8). The viral spike protein NA (red) did not show possible colocalization with EGFR. Similarly, there was no significant increase in virus binding on lung cells overexpressing DC-SIGN as compared to cells with endogenous levels of DC-SIGN (Figure 9). However, when we analyzed cells with endogenous level of receptor $\mathrm{CD} 66 \mathrm{c}$, this showed significant virus binding (Figure 10), the yellow signal in these cells suggesting strong colocalization of NA (red) with receptor CD66c (green). Additionally, upon CD66c overexpression lung cells showed a further increase in virus binding on cells as against cells with endogenous CD66c level (Figure 10) Altogether, the corresponding increase in yellow spots in cells overexpressing CD66c signifies the higher binding capacity of CD66c (green) towards Influenza A virus (NA) at the cell surface (Figure 10) as compared to that of other two glycoproteins (EGFR and DC-SIGN). An increase in virus binding to receptor leads to consequent virus entry into cells. Therefore, after virus binding experiments, we tested and compared the ability of other two glycoproteins (EGFR and DC-SIGN) in virus entry with that of CD66c, under the same experimental conditions. We observed that CD66c overexpression in lung cells resulted in significant increase in virus entry as monitored by expression levels of viral NP inside cells (Figure 11a). In contrast, overexpression of DC-SIGN and EGFR did not show much change in virus entry, except for a modest increase in viral NP (Figure 11b,c). We also found that transient overexpression of CD66c did not affect the expression levels of glycoproteins EGFR and DC-SIGN (Figure 11a). Similarly, the overexpression of these two glycoproteins (DC-SIGN and EGFR) had no effect on CD66c expression (Figure 11b,c).

\subsubsection{Absence of CD66c in Cells Showed No Decrease in Entry of Non-IAV Virus}

The membrane glycoprotein DC-SIGN has been documented to serve as a lowspecificity virus receptor for IAV and is postulated to facilitate the entry of other viruses such as HIV (Human immunodeficiency virus) and HCV (Hepatitis C virus) [11]. Critically, we argued that $\mathrm{CD} 66 \mathrm{c}$, being a membrane glycoprotein, might also be expected to serve as a low-specificity receptor for viruses other than IAV. To this effect, we sought to establish the specificity of CD66c towards influenza virus against an unrelated RNA virus, HCV. We conducted these experiments in human hepatoma Huh cells that were siRNA-mediatedsilenced for CD66c expression. We monitored HCV entry into these Huh cells by checking the expression levels of the HCV NS3 protein (Figure 12). This data clearly showed that the absence of CD66c in Huh cells had not inhibited entry of HCV, thus proving that CD66c was not a low-specificity general viral receptor.

\subsubsection{Influenza Virus Incubated with CD66c Showed Reduction in Alveolitis}

Since we had clearly shown that CD66c was capable of binding to the NA of IAV, we reasoned if we could use heterologously expressed recombinant CD66c protein to bind IAV particles, this should in principle bring down the infectivity of the virus in mice. Thus, we incubated $1 \mu \mathrm{g}$ of biologically active recombinant CD66c (rCD66c), that was produced in mouse myeloma cell lines, with $7.4 \times 10^{7} \mathrm{PFU}$ IAV before intranasal infection of BALB/c mice. After ten days of infecting mice with virus through intranasal inoculation, 
we noticed a considerable reduction in alveolitis in the mice that were infected with rCD66c bound IAV (Figure S1a) as compared to mice treated with virus alone (Figure S1b) or virus incubated with protein control Bovine Serum Albumin (BSA) (Figure S1c). The insignificant inflammation in the lungs of mice infected with CD66c treated virus was comparable to the lung tissues from uninfected mice (Figure S1d). These results strongly suggest that binding of rCD66c to NA significantly reduces lung pathology of IAV infected BALB/c mice, thus confirming our belief that CD66c is a receptor for IAV. The incubation of $1 \mu \mathrm{g}$ of biologically active recombinant $\mathrm{CD} 66 \mathrm{c}(\mathrm{rCD} 66 \mathrm{c})$ with $7.4 \times 10^{7}$ PFU IAV had shown inhibition of virus entry in human A549 lung cell line (Data not shown).
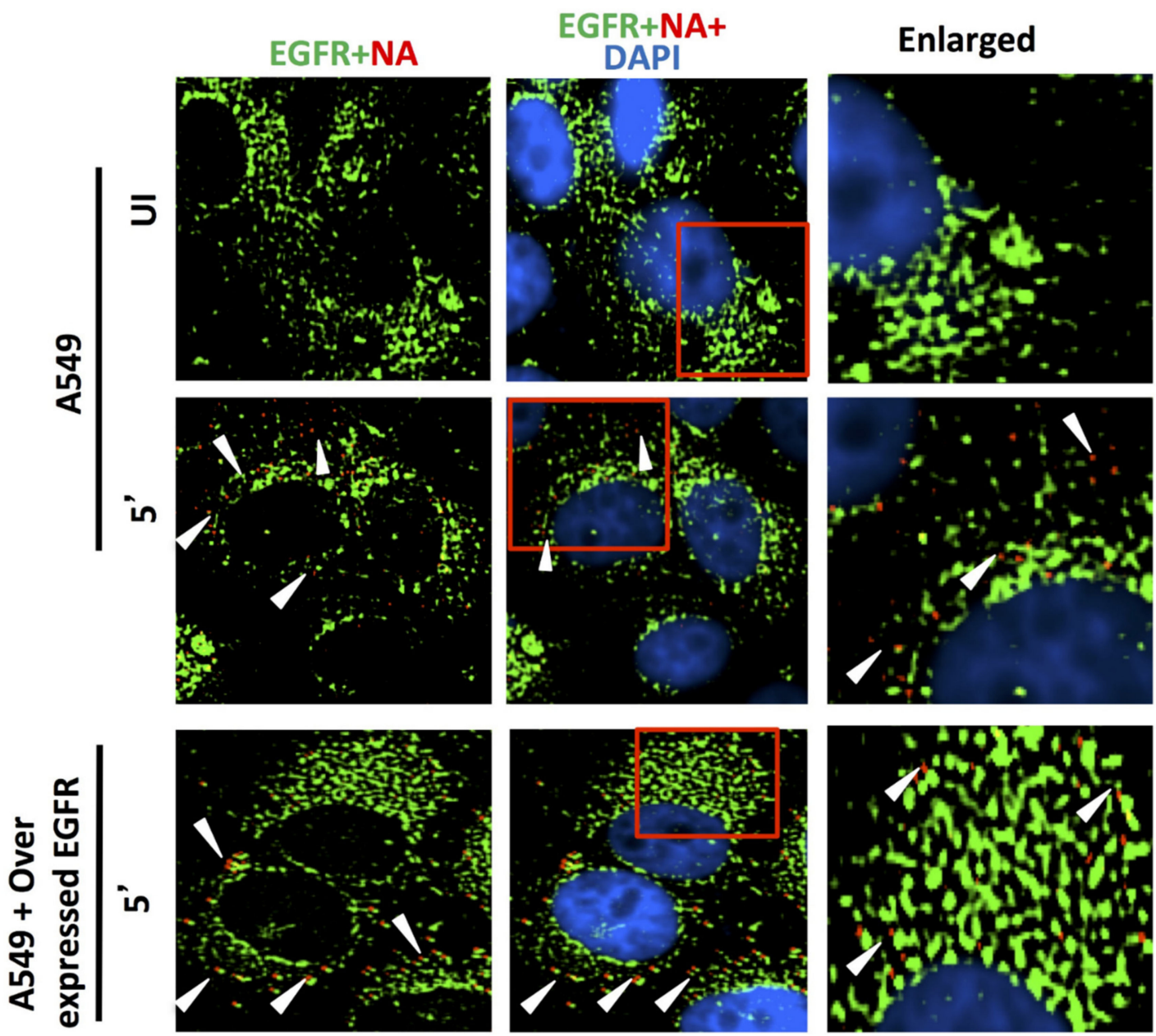

Figure 8. Comparing the ability of host membrane proteins CD66c, EGFR and DC-SIGN respectively in IAV binding on A549 cells through fluorescent microscopy. UI denotes uninfected cells; $5^{\prime}$, Cells after 5 min of virus binding. A549 cells were cultured either with endogenous level of expression or overexpression of receptor candidates EGFR, CD66c or DC-SIGN. Cells were either uninfected or infected with $5 \mathrm{MOI}$ of A/PR8/34 influenza virus for $5 \mathrm{~min}$. The secondary antibody Alexa 488 (green) probed host EGFR and Alexa 594 (red) probed influenza NA; cell nuclei are stained with DAPI (blue). No trace of virus binding in uninfected cells (top panel); modest virus binding on cell surface is observed after 5 min of incubation influenza NA (red). Only few virus particles are colocalizing with EGFR (middle panel, yellow spots, white arrow). In EGFR overexpressing A549 cells there is neither corresponding increase in virus binding nor in colocalization of viral NA with EGFR. Rather cells overexpressing EGFR show similar virus binding pattern as cells with endogenous level of EGFR (bottom panel). Altogether, virus binding is not significantly increased with overexpression of EGFR, suggesting its poor binding ability. 


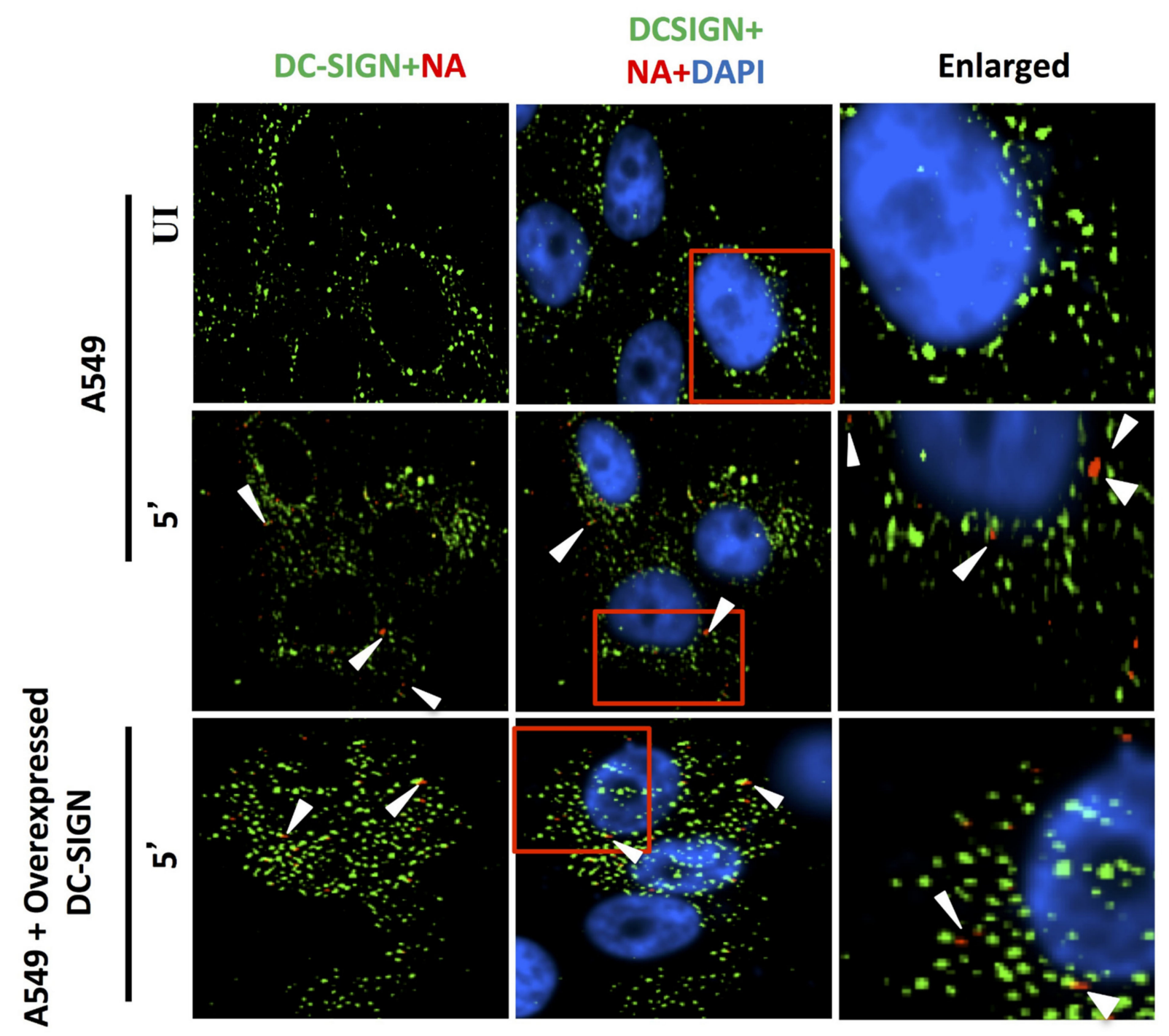

Figure 9. DC-SIGN (green) and influenza NA (red) after 5 min of virus binding. No trace of virus binding in uninfected cells (upper panel). Few co-localization spots (yellow spots, middle panel) in cells with endogenous level of DC-SIGN; in cells overexpressing DC-SIGN (green) there is no consequent increase in virus binding (bottom panel, white arrow) as compared to cells with endogenous level of DC-SIGN (middle panel, white arrow). Altogether, virus binding is not significantly increased with overexpression of DC-SIGN. 


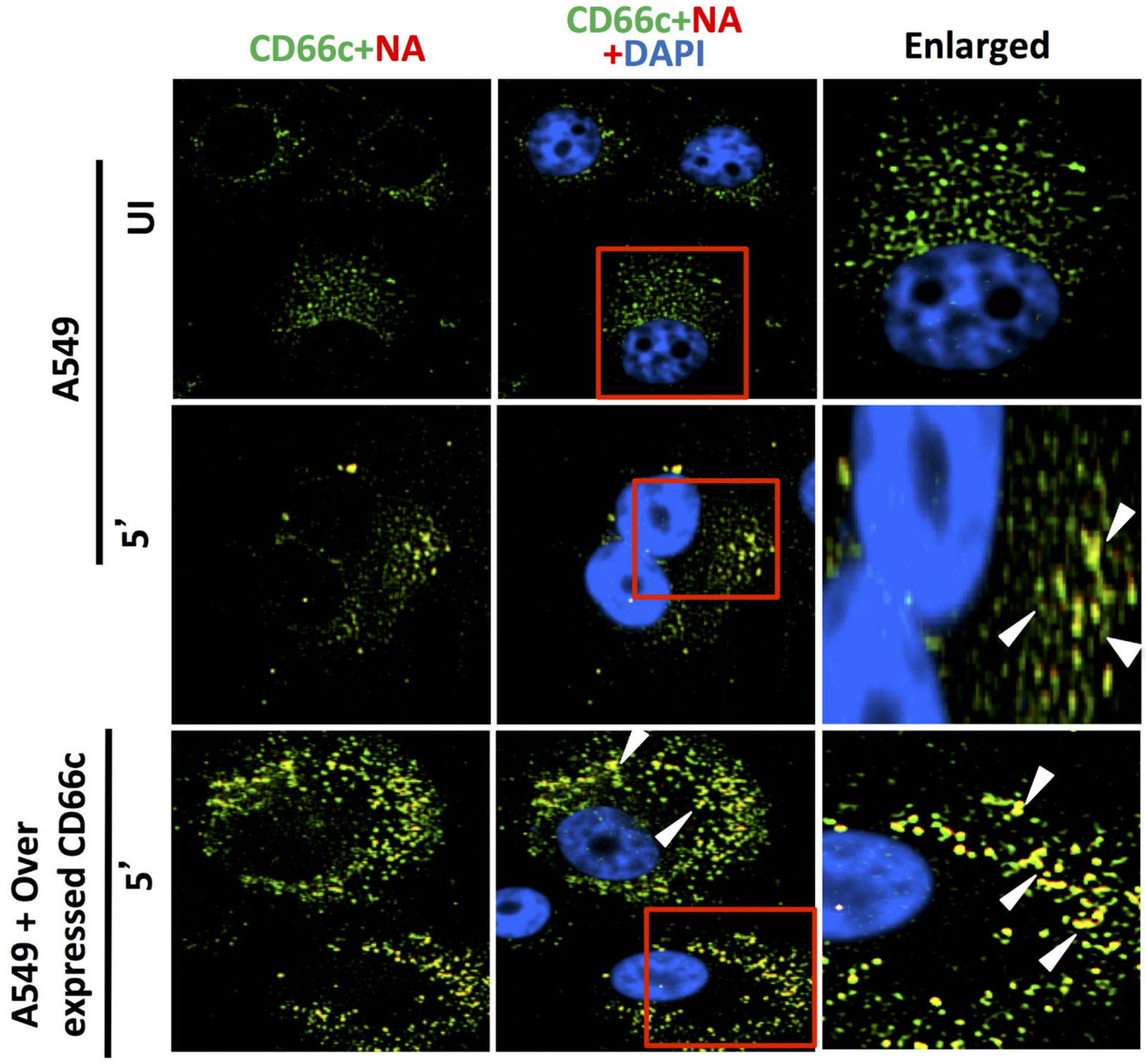

Figure 10. Cells stained for endogenous expression level of host CD66c (green) and influenza NA (red) after 5 min (5') showed significant virus binding on cell surface as probed by influenza neuraminidase NA (red) (middle panel). Cells also showed colocalization (yellow spots) between endogenous levels of receptor CD66c (green) with influenza neuraminidase NA (red). Unbound influenza NA (red) is not easily identified as most are seen merged (as yellow) with CD66c. No trace of virus binding in uninfected cells (UI, upper panel). Cells overexpressing receptor CD66c shows significant increase in virus binding and co-localization of CD66c with NA (yellow dots) on the cell surface (bottom panel) when compared to cells with endogenous level of CD66c (middle panel). CD66c (green) mainly at the periphery of cells interacting with significant number of NA (yellow after merge, white arrow). Altogether, virus binding with CD66c is prominent and significantly increased with overexpression, highlighting the strong binding ability of receptor CD66c as compared to EGFR and DC-SIGN. 
(a)

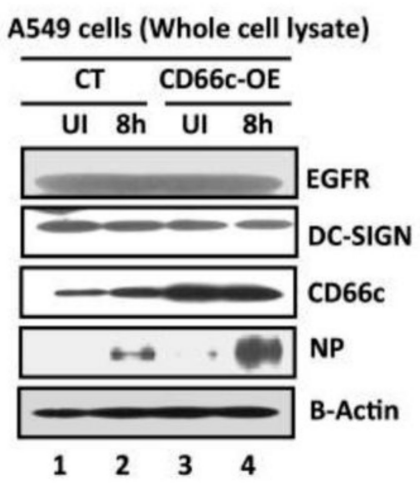

(b)

A549 cells (Whole cell lysate)

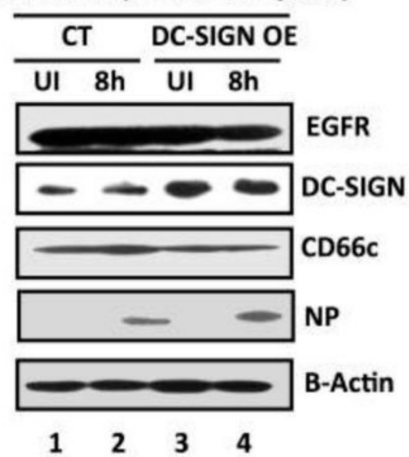

(c)

A549 cells (Whole cell lysate)

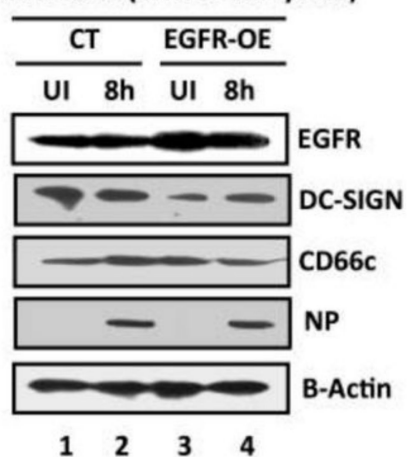

Figure 11. Comparative measurement of viral infection in cells overexpressing CD66c, EGFR and DC-SIGN respectively. CT, control A549 cells (untransfected) with endogenous levels of protein expression; CD66c-OE is A549 cells overexpressing CD66c; DC-SIGN-OE, A549 cells overexpressing DC-SIGN; EGFR-OE, A549 cells overexpressing EGFR; UI, uninfected cell groups; $8 \mathrm{~h}$, cells harvested after $8 \mathrm{~h}$ of A/PR8/34 influenza virus infection. (a) The A549 cells overexpressing CD66c (CD66c-OE) demonstrate significantly increased virus entry as against A549 cells with endogenous levels of CD66c (CT) when determined by the expression levels of viral protein NP (fourth panel from top). Top two panels in figure also show that overexpression of CD66c has not affected expression levels of EGFR and DC-SIGN, and their expression levels remained same as in untransfected A549 cells (top two panels). $\beta$-Actin is loading control. (b): cells overexpressing DC-SIGN (DC-SIGN-OE) showed a slight increase in virus entry into cells as against A549 cells with endogenous levels of DC-SIGN (CT), when determined by the level of viral NP protein (fourth panel from top). More importantly, overexpression of DC-SIGN has not increased expression levels of EGFR and CD66c, whose levels remained same as in untransfected A549 cells (top and third panel from top). $\beta$-Actin is loading control here. (c): The expression levels of viral NP protein (fourth panel from top) suggests that overexpression of EGFR in A549 cells (EGRF-OE) does not result in further increase in virus entry. The virus entry in these cells is same as in A549 cells with endogenous levels of EGFR (CT). Accordingly, overexpression of EGFR does not increase expression levels of DC-SIGN and CD66c (second and third panel from top). $\beta$-Actin is loading control. 


\section{Huh7.5 cells (Whole cell lysate) Si-CT Si-CD66c UI $48 \mathrm{~h}$ UI $48 \mathrm{~h}$
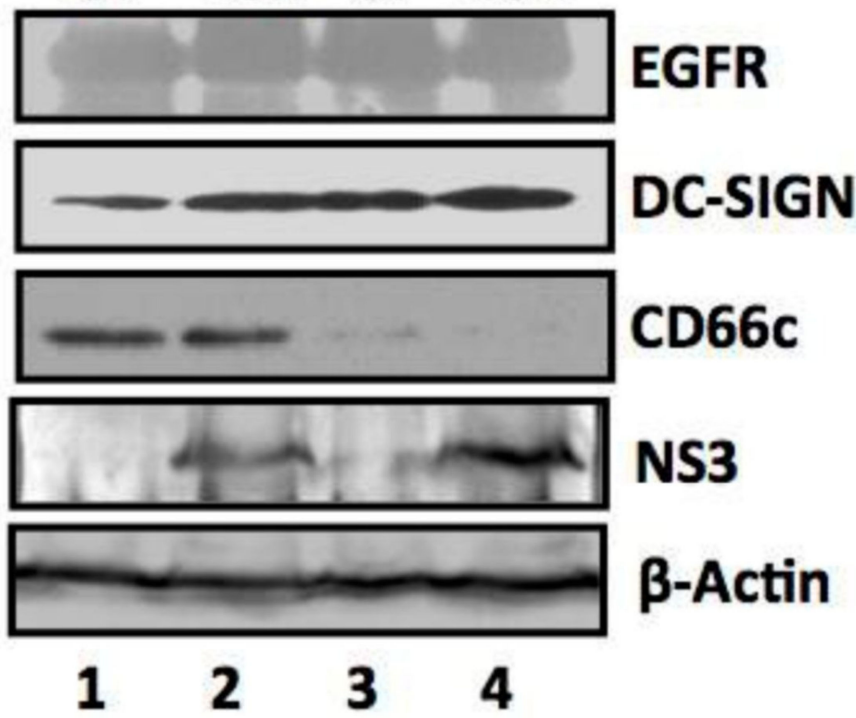

Figure 12. siRNA knockdown of CD66c in Huh7.5 cells have not inhibited entry of another non-IAV virus (Hepatitis $\mathrm{C}$ virus, $\mathrm{HCV}$ ). Here, Si-CT denotes control siRNA treated human hepatoma cells; Si-CD66c are human hepatoma cells treated with CD66c siRNA. Cells are either left uninfected (UI) or infected with $0.5 \mathrm{MOI}$ of HCV for $48 \mathrm{~h}$ ( $48 \mathrm{~h}$ ). Human hepatoma cells harvested $48 \mathrm{~h}$ post infection are subjected to immunoblotting. The figure shows that CD66c siRNA treated human hepatoma Huh7.5 cells show reduced expression of CD66c (third panel from top). However, this siRNA-mediated knockdown of CD66c in Huh7.5 cells does not inhibit HCV entry as determined by the expression level of HCV viral protein NS3 (fourth panel from top). Huh7.5 cells knocked down for CD66c expression do not show any inhibitory effect in the expression levels of EGFR and DC-SIGN (upper two panels). $\beta$-Actin is loading control.

\section{Discussion}

In our search for a receptor for IAV, we chose to follow the experimental path followed by many other research groups to identify new viral receptors [15-22]. We conducted similar experiments in detail, which could validate the interaction between viral NA and host CD66c at the outer cell surface, during IAV attachment and entry. The results thus obtained from these experiments provided sufficient evidence that suggested CD66c as the glycoprotein receptor for influenza virus. The validation of a protein receptor for influenza virus from this study provides valuable insights into some unresolved problems of influenza entry. For instance, it was cited in the earlier studies on influenza entry that although sialic acid was required for virus binding, a specific subset of glycoprotein receptors was necessary for effective viral entry [8,9], which is yet unknown. Therefore, with the results presented here, we suggest that CD66c is at least one, of the possibly many, glycoprotein receptors. Additionally, this study may further lead to the discovery of other glycoprotein receptors or co-receptors playing a role in virus entry besides CD66c. The mechanism of virus entry is poorly understood and different alternative routes were suggested for IAV entry, such as clathrin-mediated endocytosis, non clathrin-mediated, caveolin-mediated endocytosis or macropinocytosis [23-30]. We believe, CD66c, as a receptor for the influenza virus will help in elucidating the precise route for virus-entry and pave the way for discovery of other co-receptors and their mechanism.

Further, with this finding we noticed that IAV follows an infection pattern that is similar to some other viruses wherein they take advantage of adhesive properties of hosts 
cell adhesion molecules (CAMs), for their attachment and entry. For example, Coronavirus, Rabies, Reovirus and Rhinovirus, employ the following cell adhesion molecules CEACAM1, NCAM-1, JAM-A, ICAM-1 respectively, as their receptor for cellular entry [15-17]. Additionally, viruses often interact and utilize these cell adhesion molecules (CAMs) to foster a contact between infected and uninfected target cells for an effective cell-to-cell spread [31]. Carcinoembryonic Cell Adhesion Molecule 6 (CEACAM6/CD66c) as the receptor for IAV opens opportunities for further investigations on cell-to-cell spread for this virus as well. Our result showing prominent NA-CD66c interaction at the site of cell-cell junction compared to the rest of the cellular membrane is a preliminary indication in that direction (Figure 1c).

Apart from cell adhesion other unique attributes of CD66c, such as GPI anchoring, lipid raft association and heavy glycosylation (Sialyl-LewisX), make it a very suitable and strong receptor candidate for IAV entry. Influenza binding on the cell surface causes lipid raft mediated virus uptake [10], hence we suggest that this putative receptor CD66c being a component of lipid rafts bears potential to further dissect and solve the enigma of the viral internalization mechanism. In addition to that, Sialyl-LewisX is reported as the common receptor determinant of a number of influenza viruses of the terrestrial poultry [32]. Therefore, presence of Sialyl-LewisX on the CD66c molecules makes the latter a strong glycoprotein receptor candidate for the IAV. More importantly, in human lungs there is abundant expression of CEACAM6 by alveolar and bronchial epithelial cells, where it also demonstrates surfactant association and secretion into lung-lining fluid [33]. These features of $\mathrm{CD} 66 \mathrm{c}$ with respect to human lungs make this molecule vulnerable to respiratory pathogens like IAV. More importantly, like other CEACAMs, which are receptors for respiratory pathogens (bacteria) including Haemophilus influenzae and Moraxella catarrhalis [34,35], CEACAM6 (CD66c) from above results, serves as a receptor for yet another respiratory pathogen - IAV.

It is reported that when pathogens interact with the CEACAM receptors, there is significant activation of PI3K signaling during internalization of the pathogen [36]. In our previous report, we validated the activation of PI3k/Akt pathways when CEACAM6 (CD66c) interacts with influenza NA [12], here we demonstrate viral internalization upon NA-CD66c interaction at the cell surface. The NA-CD66c interaction was studied in detail through yeast-two-hybrid system, in vitro expression, pull down assays and this interaction was conserved for other strains of influenza as well [12]. During yeast two hybrid lung cDNA library screen, of the two surface proteins, only Neuraminidase showed interaction with CD66c [12]. Also, this new finding on CD66c provides support to the viewpoint of a contentious argument made in the past on a role for NA in influenza entry $[37,38]$.

More importantly, viruses frequently exploit chemokine receptors, some CD markers and other membrane glycoproteins of IgSF as their receptors for entry and also for manipulating the host defense mechanism [39]. For this reason, a majority of these immunomodulatory studies get direct reference to viral infections or immune evasion, at the entry stage, which are to a great extent, centric to the interaction of the viral spike glycoproteins with such cellular receptors and co-receptors. It is important to mention here that, the receptor CD66c is also a member of IgSF and plays a number of crucial immunomodulatory roles in human. To cite a few examples, during multiple myeloma CD66c inhibits cytotoxic $\mathrm{T}$ cell activation, in normal neutrophils it is known as an activation marker that stimulates neutrophil signaling [40,41]. Further, CD66c increases apoptosis in B-cell precursor acute lymphoblastic leukemia cells [42]. Another set of evidence on the expression of CEACAMs in human lung and their modulated co-expression by type I and type II interferon was reported recently [35,43]. Altogether these studies establish CD66c as an active immunomodulatory molecule playing a significant role in innate and adaptive immunity in human. Accordingly, for being an active immunomodulatory molecule and with presence on T cells and Macrophages, we took elements of caution into consideration while designing animal experiments and interpreting data thereof (Figure S1). 
Therefore, we argue that immunomodulatory studies carried out earlier in abeyance of any glycoprotein receptor for IAV were rather incomplete and CD66c at the helm of immunomodulation and its interaction with virus during internalization has potential to unfold the precise mechanism of influenza infection, consequent immune response and cell tropism. Lack of any identified glycoprotein receptor during IAV attachment and entry, had greatly limited influenza research discourse in this direction whereas similar questions had been addressed well with other viruses [44].

Supplementary Materials: The following are available online at https:/ /www.mdpi.com/article/10 .3390/v13050726/s1, Figure S1: PR8 virus pre-incubated with purified recombinant CD66c causes lower inflammatory response in mice lung.

Author Contributions: S.K.R. and S.K.L. conceived, planned and orchestrated the project. S.K.R. planned and optimized antibody mediated cell blockade experiments in human lung A549 cells. S.K.R. performed other experiments carried out in A549 and lec2CHO cell lines. P.G. performed experiments in NIH3T3 cell lines. M.A.A. performed comparative binding, entry of IAV with reference to CD66c, EGFR, DC-SIGN and siRNA (against CD66c expression) experiments to compare entry of IAV and HCV. I.A., C.C., and S.C. performed virus experiments in mice. D.K.V. performed virus entry experiment in HEK cells. S.K.R. prepared first draft of the manuscript. S.K.R., N.N., A.S. and S.K.L. further improved the manuscript from inputs of other authors. S.K.R., M.A.A., D.W., and S.K.L. critically analyzed the datasets. All authors have read and agreed to the published version of the manuscript.

Funding: The study was supported by research grants to SKL from Council of Scientific and Industrial Research (CSIR) and The Department of Biotechnology, Government of India. The research was also partly supported by the core grants to The International Centre for Genetic Engineering and Biotechnology (ICGEB).

Institutional Review Board Statement: The permission to perform the animal experiments was given by Panjab University (Microbiology Department, Chandigarh, 160014, India) Institutional Animal Ethics Committee vide letter no. IAEC/282 Dated 30/08/2012.

Data Availability Statement: Data is contained within the article and Supplementary Materials.

Acknowledgments: S.K.R. was awarded CSIR JRF funding. The plasmid pRc/CMV with untagged CD66c was a generous gift from Wolfgang Zimmermann (Tumor Immunology Laboratory Life Center, University Clinic-Grosshadern Muenchen, Germany). The authors thank Professor Maddy Parsons, King's College London for EGFR-GFP Plasmid. We thank Aftab Ahmad, University of Alabama at Birmingham for A549 cells, Joseph Reynolds for PR8 whole virus and Balaji Manicassamy (UIC, Chicago) for antisera raised against purified and disrupted PR8 virus. The authors thank Purnima Kumar (ICGEB), Ravinder Kumar (ICGEB) and Jyoti Batra (ICGEB) for their help with the reagents and media preparation. Initial support from Sultan Tousif (ICGEB) during flow cytometry measurements is duly acknowledged.

Conflicts of Interest: The authors declare no competing interests.

\section{References}

1. Varki, A. Glycan-based interactions involving vertebrate sialic-acid-recognizing proteins. Nature 2007, 446, 1023-1029. [CrossRef] [PubMed]

2. Varki, A. Biological roles of oligosaccharides: All of the theories are correct. Glycobiology 1993, 3, 97-130. [CrossRef] [PubMed]

3. Schauer, R. Sialic acids as regulators of molecular and cellular interactions. Curr. Opin. Struct. Biol. 2009, 19, 507-514. [CrossRef] [PubMed]

4. Matrosovich, M.; Herrler, G.; Klenk, H.D. Sialic Acid Receptors of Viruses. Top. Curr. Chem. 2015, 367, 1-28. [PubMed]

5. Mercer, J.; Schelhaas, M.; Helenius, A. Virus entry by endocytosis. Annu. Rev. Biochem. 2010, 79, 803-833. [CrossRef]

6. Gottschalk, A. The Viruses: Biochemical Biological and Biophysical Properties; Burnet, F.M., Stanley, W.M., Eds.; Academic: New York, NY, USA, 1959; Volume 3, pp. 51-61.

7. Londrigan, S.L.; Turville, S.G.; Tate, M.D.; Deng, Y.M.; Brooks, A.G.; Reading, P.C. N-linked glycosylation facilitates sialic acid-independent attachment and entry of influenza A viruses into cells expressing DC-SIGN or L-SIGN. J. Virol. 2011, 85, 2990-3000. [CrossRef]

8. De Vries, E.; de Vries, R.P.; Wienholts, M.J.; Floris, C.E.; Jacobs, M.S.; van den Heuvel, A.; Rottier, P.J.; de Haan, C.A.E. Influenza A virus entry into cells lacking sialylated N-glycans. Proc. Natl. Acad. Sci. USA 2012, 109, 7457-7462. [CrossRef] 
9. Chu, V.C.; Whittaker, G.R. Influenza virus entry and infection require host cell N-linked glycoprotein. Proc. Natl. Acad. Sci. USA 2004, 101, 18153-18158. [CrossRef]

10. Eierhoff, T.; Hrincius, E.R.; Rescher, U.; Ludwig, S.; Ehrhardt, C. The epidermal growth factor receptor (EGFR) promotes uptake of influenza A viruses (IAV) into host cells. PLoS Pathog. 2010, 6, e1001099. [CrossRef]

11. Lozach, P.Y.; Burleigh, L.; Staropoli, I.; Amara, A. The C type lectins DC-SIGN and L-SIGN: Receptors for viral glycoproteins Methods Mol. Biol. 2007, 379, 51-68. [CrossRef]

12. Gaur, P.; Ranjan, P.; Sharma, S.; Patel, J.R.; Bowzard, J.B.; Rahman, S.K.; Kumari, R.; Gangappa, S.; Katz, J.M.; Cox, N.J.; et al. Influenza A virus neuraminidase protein enhances cell survival through interaction with carcinoembryonic antigen-related cell adhesion molecule 6 (CEACAM6) protein. J. Biol. Chem. 2012, 287, 15109-15117. [CrossRef] [PubMed]

13. Baniasadi, V.; Lal, S.K. A novel method to produce Influenza A virus matrix protein M1 Capsid Like Particles (CLPs). J. Virol. Methods 2014, 205C, 1-2. [CrossRef] [PubMed]

14. Medina, R.A.; Stertz, S.; Manicassamy, B.; Zimmermann, P.; Sun, X.; Albrecht, R.A.; Uusi-Kerttula, H.; Zagordi, O.; Belshe, R.B.; Frey, S.E.; et al. Glycosylations in the globular head of the hemagglutinin protein modulate the virulence and antigenic properties of the H1N1 influenza viruses. Sci. Transl. Med. 2013, 5, 187ra70. [CrossRef]

15. Barton, E.S.; Forrest, J.C.; Connolly, J.L.; Chappell, J.D.; Liu, Y.; Schnell, F.J.; Nusrat, A.; Parkos, C.A.; Dermody, T.S. Junction adhesion molecule is a receptor for reovirus. Cell 2001, 104, 441-451. [CrossRef]

16. Staunton, D.E.; Merluzzi, V.J.; Rothlein, R.; Barton, R.; Marlin, S.D.; Springer, T.A. A cell adhesion molecule, ICAM-1, is the major surface receptor for rhinoviruses. Cell 1989, 56, 849-853. [CrossRef]

17. Dermody, T.S.; Kirchner, E.; Guglielmi, K.M.; Stehle, T. Immunoglobulin superfamily virus receptors and the evolution of adaptive immunity. PLoS Pathog. 2009, 5, e1000481. [CrossRef]

18. Coyne, C.B.; Bergelson, J.M. Virus-induced Abl and Fyn kinase signals permit coxsackievirus entry through epithelial tight junctions. Cell 2006, 124, 119-131. [CrossRef]

19. Maddon, P.J.; Dalgleish, A.G.; McDougal, J.S.; Clapham, P.R.; Weiss, R.A.; Axel, R. The T4 gene encodes the AIDS virus receptor and is expressed in the immune system and the brain. Cell 1986, 47, 333-348. [CrossRef]

20. Evans, M.J.; von Hahn, T.; Tscherne, D.M.; Syder, A.J.; Panis, M.; Wolk, B.; Hatziioannou, T.; McKeating, J.A.; Bieniasz, P.D.; Rice, C.M. Claudin-1 is a hepatitis C virus co-receptor required for a late step in entry. Nature 2007, 446, 801-805. [CrossRef]

21. Mendelsohn, C.L.; Wimmer, E.; Racaniello, V.R. Cellular receptor for poliovirus: Molecular cloning, nucleotide sequence, and expression of a new member of the immunoglobulin superfamily. Cell 1989, 56, 855-865. [CrossRef]

22. Geraghty, R.J.; Krummenacher, C.; Cohen, G.H.; Eisenberg, R.J.; Spear, P.G. Entry of alphaherpesviruses mediated by poliovirus receptor-related protein 1 and poliovirus receptor. Science 1998, 280, 1618-1620. [CrossRef]

23. De Vries, E.; Tscherne, D.M.; Wienholts, M.J.; Cobos-Jiménez, V.; Scholte, F.; García-Sastre, A.; Rottier, P.J.; de Haan, C.A. Dissection of the influenza A virus endocytic routes reveals macropinocytosis as an alternative entry pathway. PLoS Pathog. 2011, 7, e1001329. [CrossRef]

24. Sieczkarski, S.B.; Whittaker, G.R. Influenza virus can enter and infect cells in the absence of clathrin-mediated endocytosis. J. Virol. 2002, 76, 10455-10464. [CrossRef]

25. Lakadamyali, M.; Rust, M.J.; Zhuang, X. Endocytosis of influenza viruses. Microbes Infect. 2004, 6, 929-936. [CrossRef]

26. Lakadamyali, M.; Rust, M.J.; Babcock, H.P.; Zhuang, X. Visualizing infection of individual influenza viruses. Proc. Natl. Acad. Sci. USA 2003, 100, 9280-9285. [CrossRef]

27. Rust, M.J.; Lakadamyali, M.; Zhang, F.; Zhuang, X. Assembly of endocytic machinery around individual influenza viruses during viral entry. Nat. Struct. Mol. Biol. 2004, 11, 567-573. [CrossRef]

28. Matlin, K.S.; Reggio, H.; Helenius, A.; Simons, K. Infectious entry pathway of influenza virus in a canine kidney cell line. J. Cell Biol. 1981, 91 Pt 1, 601-613. [CrossRef]

29. Sieczkarski, S.B.; Whittaker, G.R. Differential requirements of Rab5 and Rab7 for endocytosis of influenza and other enveloped viruses. Traffic 2003, 4, 333-343. [CrossRef]

30. Khor, R.; McElroy, L.J.; Whittaker, G.R. The ubiquitin-vacuolar protein sorting system is selectively required during entry of influenza virus into host cells. Traffic 2003, 4, 857-868. [CrossRef]

31. Mothes, W.; Sherer, N.M.; Jin, J.; Zhong, P. Virus cell-to-cell transmission. J. Virol. 2010, 84, 8360-8368. [CrossRef]

32. Gambaryan, A.S.; Tuzikov, A.B.; Pazynina, G.V.; Desheva, J.A.; Bovin, N.V.; Matrosovich, M.N.; Klimov, A.I. 6-sulfo sialyl Lewis X is the common receptor determinant recognized by $\mathrm{H} 5, \mathrm{H} 6, \mathrm{H} 7$ and $\mathrm{H} 9$ influenza viruses of terrestrial poultry. Virol. J. 2008, 5, 85. [CrossRef] [PubMed]

33. Kolla, V.; Gonzales, L.W.; Bailey, N.A.; Wang, P.; Angampalli, S.; Godinez, M.H.; Madesh, M.; Ballard, P.L. Carcinoembryonic cell adhesion molecule 6 in human lung: Regulated expression of a multifunctional type II cell protein. Am. J. Physiol. Lung Cell Mol. Physiol. 2009, 296, L1019-L1030. [CrossRef] [PubMed]

34. Hill, D.J.; Virji, M. A novel cell-binding mechanism of Moraxella catarrhalis ubiquitous surface protein UspA: Specific targeting of the N-domain of carcinoembryonic antigen-related cell adhesion molecules by UspA1. Mol. Microbiol. 2003, 48, 117-129. [CrossRef] [PubMed] 
35. Klaile, E.; Klassert, T.E.; Scheffrahn, I.; Muller, M.M.; Heinrich, A.; Heyl, K.A.; Dienemann, H.; Grunewald, C.; Bals, R.; Singer, B.B. Carcinoembryonic antigen (CEA)-related cell adhesion molecules are co-expressed in the human lung and their expression can be modulated in bronchial epithelial cells by non-typable Haemophilus influenzae, Moraxella catarrhalis, TLR3, and type I and II interferons. Respir. Res. 2013, 14, 85. [CrossRef]

36. Voges, M.; Bachmann, V.; Naujoks, J.; Kopp, K.; Hauck, C.R. Extracellular Ig C2 $_{2}$ constant domains of CEACAMs mediate PI3K sensitivity during uptake of pathogens. PLoS ONE 2012, 7, e39908. [CrossRef]

37. Matrosovich, M.N.; Matrosovich, T.Y.; Gray, T.; Roberts, N.A.; Klenk, H.D. Neuraminidase is important for the initiation of influenza virus infection in human airway epithelium. J. Virol. 2004, 78, 12665-12667. [CrossRef]

38. Ohuchi, M.; Asaoka, N.; Sakai, T.; Ohuchi, R. Roles of neuraminidase in the initial stage of influenza virus infection. Microbes Infect./Inst. Pasteur 2006, 8, 1287-1293. [CrossRef]

39. Alcami, A. Viral mimicry of cytokines, chemokines and their receptors. Nat. Rev. Immunol. 2003, 3, 36-50. [CrossRef]

40. Skubitz, K.M.; Campbell, K.D.; Skubitz, A.P. CD66a, CD66b, CD66c, and CD66d each independently stimulate neutrophils. J. Leukoc. Biol. 1996, 60, 106-117. [CrossRef]

41. Witzens-Harig, M.; Hose, D.; Junger, S.; Pfirschke, C.; Khandelwal, N.; Umansky, L.; Seckinger, A.; Conrad, H.; Brackertz, B.; Reme TGueckel, B.; et al. Tumor cells in multiple myeloma patients inhibit myeloma-reactive T cells through carcinoembryonic antigen-related cell adhesion molecule-6. Blood 2013, 121, 4493-4503. [CrossRef]

42. Kanderova, V.; Hrusak, O.; Kalina, T. Aberrantly expressed CEACAM6 is involved in the signaling leading to apoptosis of acute lymphoblastic leukemia cells. Exp. Hematol. 2010, 38, 653-660. [CrossRef]

43. Fahlgren, A.; Baranov, V.; Frangsmyr, L.; Zoubir, F.; Hammarstrom, M.L.; Hammarstrom, S. Interferon-gamma tempers the expression of carcinoembryonic antigen family molecules in human colon cells: A possible role in innate mucosal defense. Scand. J. Immunol. 2003, 58, 628. [CrossRef]

44. Berger, E.A.; Murphy, P.M.; Farber, J.M. Chemokine receptors as HIV-1 coreceptors: Roles in viral entry, tropism, and disease. Annu. Rev. Immunol. 1999, 17, 657-700. [CrossRef] 